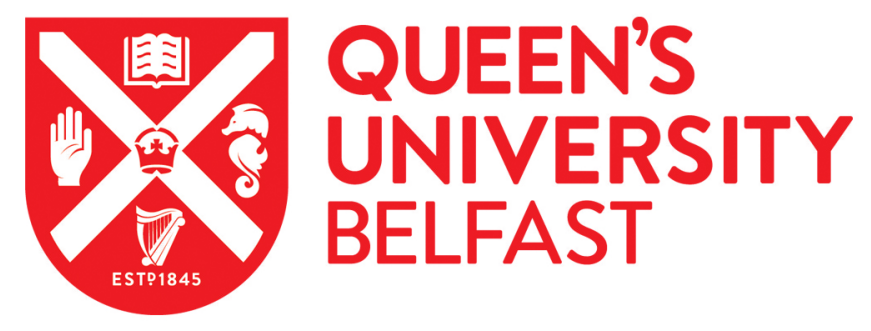

\title{
Low pressure carbon dioxide solubility in lithium-ion batteries based electrolytes as a function of temperature. Measurement and prediction
}

Dougassa, Y. R., Tessier, C., El Ouatani, L., Anouti, M., \& Jacquemin, J. (2013). Low pressure carbon dioxide solubility in lithium-ion batteries based electrolytes as a function of temperature. Measurement and prediction. The Journal of Chemical Thermodynamics, 61, 32-44. https://doi.org/10.1016/j.jct.2012.12.025

Published in:

The Journal of Chemical Thermodynamics

Document Version:

Peer reviewed version

Queen's University Belfast - Research Portal:

Link to publication record in Queen's University Belfast Research Portal

\section{Publisher rights}

This is the author's version of a work that was accepted for publication in The Journal of Chemical Thermodynamics. Changes resulting from the publishing process, such as peer review, editing, corrections, structural formatting, and other quality control mechanisms may not be reflected in this document. Changes may have been made to this work since it was submitted for publication. A definitive version was subsequently published in The Journal of Chemical Thermodynamics, [VOL 61, (2013)]

\section{General rights}

Copyright for the publications made accessible via the Queen's University Belfast Research Portal is retained by the author(s) and / or other copyright owners and it is a condition of accessing these publications that users recognise and abide by the legal requirements associated with these rights.

Take down policy

The Research Portal is Queen's institutional repository that provides access to Queen's research output. Every effort has been made to ensure that content in the Research Portal does not infringe any person's rights, or applicable UK laws. If you discover content in the Research Portal that you believe breaches copyright or violates any law, please contact openaccess@qub.ac.uk. 


\section{Accepted Manuscript}

Low pressure carbon dioxide solubility in lithium-ion batteries based electrolytes as a function of temperature. Measurement and prediction

Yvon Rodrigue Dougassa, Cécile Tessier, Loubna El Ouatani, Mérièm Anouti, Johan Jacquemin

PII:

S0021-9614(13)00018-9

DOI: http://dx.doi.org/10.1016/j.jct.2012.12.025

Reference: YJCHT 3409

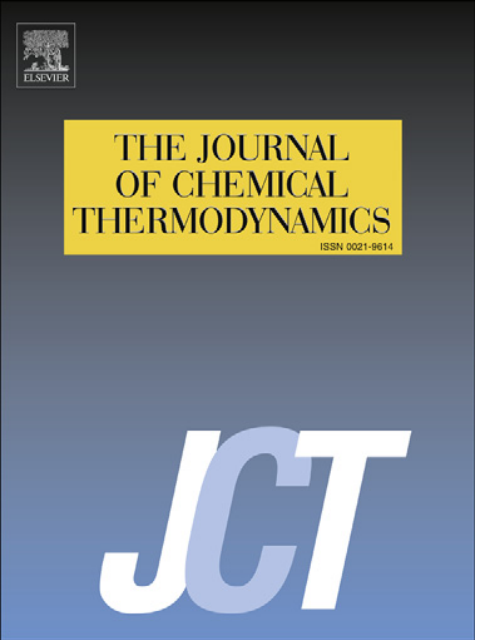

To appear in:

J. Chem. Thermodynamics

Received Date: $\quad 16$ December 2012

Accepted Date: $\quad 31$ December 2012

Please cite this article as: Y.R. Dougassa, C. Tessier, L.E. Ouatani, M. Anouti, J. Jacquemin, Low pressure carbon dioxide solubility in lithium-ion batteries based electrolytes as a function of temperature. Measurement and prediction, J. Chem. Thermodynamics (2013), doi: http://dx.doi.org/10.1016/j.jct.2012.12.025

This is a PDF file of an unedited manuscript that has been accepted for publication. As a service to our customers we are providing this early version of the manuscript. The manuscript will undergo copyediting, typesetting, and review of the resulting proof before it is published in its final form. Please note that during the production process errors may be discovered which could affect the content, and all legal disclaimers that apply to the journal pertain. 
Low pressure carbon dioxide solubility in lithium-ion

batteries based electrolytes as a function of temperature. Measurement and prediction

\author{
Yvon Rodrigue Dougassa, ${ }^{1}$ Cécile Tessier, ${ }^{2}$ Loubna El Ouatani, ${ }^{2}$ \\ Mérièm Anouti, 1,* and Johan Jacquemin ${ }^{3, *}$
}

\begin{abstract}
${ }^{1}$ Université François Rabelais, Laboratoire PCMB (EA 4244), équipe Chimie-physique des Interfaces et des Milieux Electrolytiques (CIME), Parc de Grandmont, 37200 Tours, France.

${ }^{2}$ Direction de la Recherche - SAFT, SAFT, 33000 Bordeaux, France.

${ }^{3}$ CenTACat, School of Chemistry and Chemical Engineering, Queen's University Belfast, Belfast, BT9 5AG Northern Ireland, UK.
\end{abstract}

\footnotetext{
* corresponding authors: meriem.anouti@univ-tours.fr ; johan.jacquemin@qub.ac.uk

* corresponding authors: meriem.anouti@univ-tours.fr ; johan.jacquemin@qub.ac.uk
} 


\section{Abstract}

We present in this study the effect of nature and concentration of lithium salt, such as the lithium hexafluorophosphate, $\mathrm{LiPF}_{6}$; lithium tris(pentafluoroethane)trifluorurophosphate LiFAP; lithium bis(trifluoromethylsulfonyl)imide, LiTFSI, on the $\mathrm{CO}_{2}$ solubility in four electrolytes for lithium ion batteries based on pure solvent that include ethylene carbonate (EC), dimethyl carbonate (DMC), ethyl methyl carbonate (EMC), diethyl carbonate (DEC), as well as, in the EC:DMC, EC:EMC and EC:DEC (50:50) wt \% binary mixtures as a function of temperature from (283 to 353 ) $\mathrm{K}$ and atmospheric pressure. Based on experimental solubility values, the Henry's law constant of the carbon dioxide in these solutions with the presence or absence of lithium salt was then deduced and compared with reported values from the literature, as well as with those predicted by using COSMO-RS methodology within COSMOthermX software. From this study, it appears that the addition of $1 \mathrm{~mol} \cdot \mathrm{dm}^{-3} \mathrm{LiPF}_{6}$ salt in alkylcarbonate solvents decreases their $\mathrm{CO}_{2}$ capture capacity. By using the same experimental conditions, an opposite $\mathrm{CO}_{2}$ solubility trend was generally observed in the case of the addition of LiFAP or LiTFSI salts in these solutions. Additionally, in all solutions investigated during this work, the $\mathrm{CO}_{2}$ solubility is greater in electrolytes containing the LiFAP salt, followed by those based on the LiTFSI case. The precision and accuracy of the experimental data reported therein, which are close to (1 and 15) \%, respectively. From the variation of the Henry's law constant with temperature, the partial molar thermodynamic functions of dissolution such as the standard Gibbs energy, the enthalpy, and the entropy, as well as the mixing enthalpy of the solvent with $\mathrm{CO}_{2}$ in its hypothetical liquid state were calculated. Finally, a quantitative analysis of the $\mathrm{CO}_{2}$ solubility evolution was carried out in the EC:DMC (50:50) wt \% binary mixture as the function of the $\mathrm{LiPF}_{6}$ or LiTFSI concentration in solution to elucidate how ionic species modify the $\mathrm{CO}_{2}$ solubility in alkylcarbonates-based Li-ion electrolytes by investigating the salting effects at $T=298.15 \mathrm{~K}$ and atmospheric pressure.

\section{Keywords}

Solubility, $\mathrm{CO}_{2}$, $\mathrm{LiPF}_{6}$, LiTFSI, LiFAP, alkylcarbonate, lithium-ion batteries 
1

2

3

4

5

6

7

8

10

11

12

13

14

15

16

17

18

19

20

21

22

23

24

25

26

27

28

29

30

31

32

33

34

35

36

37

38

39

40

41

42

43

44

45

46

47

48

49

50

51

52

53

54

55

56

57

58

59

60

61

62

63

64

65 


\section{Introduction}

Most liquid electrolytes used in commercial lithium-ion batteries are obtained by dissolving a lithium salt in a specific alkylcarbonate mixture. Currently, the most suitable electrolytes for lithium ion battery remain the mixture of the lithium hexafluorophosphate, $\mathrm{LiPF}_{6}$ with cyclic carbonates like ethylene carbonate (EC) or propylene carbonate (PC) and linear carbonates such as dimethyl carbonate (DMC), ethyl methyl carbonate (EMC) and diethyl carbonate (DEC) [1]. However, it is well described into the literature that $\mathrm{LiPF}_{6}$ is thermally unstable and decomposes in LiF and $\mathrm{PF}_{5}$, as well as, that $\mathrm{LiPF}_{6}$ and $\mathrm{PF}_{5}$ can react with residual water to form HF [2-4]. Despite these technological issues, $\mathrm{LiPF}_{6}$ is still used as the reference salt in Li-ion batteries for more than a decade because of its unique properties in $\mathrm{Li}$-ion devices providing good ionic conductivity of the electrolyte, as well as, based-on its ability to passivate an aluminium current collector, and to participate to the passivation layer on the negative electrode [5-7]. Furthermore, the selection of another safer lithium salt to be dissolved in alkylcarbonates is of great importance, but this change influences the physical, thermal and transport properties of the electrolyte [8,9]. According to the structure similarity between the hexafluorophosphate and tris(pentafluoroethane)trifluorophosphate anions, the lithium tris(pentafluoroethane)trifluorophosphate LiFAP, is currently investigated by several groups to limit potentially these property changes [6]. Lithium imide salts are also potentially a good alternative to $\mathrm{LiPF}_{6}$ since these salts could both improve the chemical and thermal stability of the electrolyte. Particularly, the lithium bis(trifluoromethylsulfonyl)imide, LiTFSI salt, which is well known to be more stable and safer than $\mathrm{LiPF}_{6}$ [10], even if it were clearly pointed-out in the literature that LiTFSI salt is more corrosive than $\mathrm{LiPF}_{6}$ towards the aluminium collector [11-14]. Additionally, the performance of a lithium ion battery depends also to a great extent on the stability of electrolyte solution, because the high voltage of the battery may cause the decomposition of lithium salt or organic solvents [15-17]. This decomposition of the electrolyte limits the battery lifetime [18,19]. For example, it is reported in the literature that the oxidation reaction of the Li-ion electrolyte at high potentials leads to the formation of $\mathrm{CO}_{2}$ when high potentials are applied to the electrode, which increases the pressure inside the sealed cell [19-21]. Furthermore, the carbon dioxide formation also 
changes the composition of the electrolyte driven by the solubility of the carbon dioxide in this solution. These effects caused by the formation of the carbon dioxide can be evaluated with the prior knowledge of the $\mathrm{CO}_{2}$ solubility in electrolyte solutions. Furthermore, the salt selection and effects on the $\mathrm{CO}_{2}$ solubility in electrolytes can be analysed in detail by comparing the $\mathrm{CO}_{2}$ solubility in solutions with or without a lithium salt. Many authors have reported in the literature the $\mathrm{CO}_{2}$ solubility in classical alkylcarbonate solvents [22-38], but generally, these studies are basically focused on pure alkylcarbonate solvents and on their mixtures without the presence of lithium salt. However, the $\mathrm{CO}_{2}$ solubility in classical Li-ion electrolytes depends not only on the pressure and temperature, but also on the salt structure and its concentration in solution. The salting effect in solvents containing a specific salt needs to be investigated, nevertheless, to date very few $\mathrm{CO}_{2}$ solubility data in alkylcarbonate are available in the literature, especially for solutions containing lithium salts.

Herein, we report first, the solubility of carbon dioxide in eight lithium ion batteries based electrolytes containing $1 \mathrm{~mol} \cdot \mathrm{dm}^{-3}$ lithium salt, $\mathrm{LiPF}_{6}$ or LiTFSI, dissolved in a pure alkylcarbonate solvent, EC, DMC, EMC, DEC, as a function of temperature from (283 to 353) $\mathrm{K}$ and atmospheric pressure. The comparison of these experimental results along with those reported previously by our group in the case of the $\mathrm{CO}_{2}$ solubility in pure carbonate solvents $[22,23]$ permits the quantification of the effect of the presence of lithium salt on the carbon dioxide absorption by the pure carbonate solvent. Secondly, by using the same methodology, we report in this paper the effect of the presence or the absence of $1 \mathrm{~mol} \cdot \mathrm{dm}^{-3}$ lithium salt $\left(\mathrm{LiPF}_{6}, \mathrm{LiTFSI}\right.$ or LiFAP) on the $\mathrm{CO}_{2}$ solubility in three different (50:50) wt \% binary mixtures of alkylcarbonate solvents such as EC:DMC, EC:EMC and EC:DEC as a function of temperature. From these results, Henry's law constants and dissolution properties to include the Gibbs energy, the standard enthalpy and entropy of dissolution, as well as the mixing enthalpy of the solvent with $\mathrm{CO}_{2}$ in its hypothetical liquid state were then deduced. Thirdly, we present a quantitative analysis of the $\mathrm{CO}_{2}$ solubility evolution with the salting effects in the EC:DMC (50:50) wt \% binary mixture as the function of the $\mathrm{LiPF}_{6}$ or LiTFSI concentration in solution. Finally, the $\mathrm{CO}_{2}$ solubility in these electrolytes has been then calculated by the COSMO-RS methodology by using directly the COSMOthermX chemical engineering software. These calculated values are then compared with 
experimental values to evaluate the predictive capability of the $\mathrm{CO}_{2}$ solubility in electrolytes for Li-ion batteries applications.

\section{Experimental}

\subsection{Materials and mixtures preparations}

Highly pure (GC grade, mass fraction purity > 0.9999) ethylene carbonate (EC), dimethylcarbonate (DMC), ethyl methyl carbonate (EMC), and diethyl carbonate (DEC) were obtained from Aldrich and were used as received. The highly pure (mass fraction 0.9999 lithium salts such as: lithium hexafluorophosphate $\left(\mathrm{LiPF}_{6}\right)$ and lithium bis(trifluoromethylsulfonyl)imide (LiTFSI) purchased from Sigma Aldrich and from Solvionic, respectively, were kept and used under a dry atmosphere in a glove box. All electrolytes containing the LiFAP salt were purchased from Merck with mass fraction purity greater than 0.9999. All LiFAP electrolytes were kept and used under a dry atmosphere in a glove box and then were used as received from the manufacturer.

Studied solvents mixtures were prepared by mass with an accuracy of $\pm 1 \times 10^{-4} \mathrm{~g}$ using a Sartorius 1602 MP balance under a dry atmosphere in a glove box, and kept inside the glove box before further analyses. Alkylcarbonate mixtures studied into this work have been prepared by mass at $25{ }^{\circ} \mathrm{C}$ and are denoted in mass fraction as follow: EC:DMC (50:50) wt \%, EC:EMC (50:50) wt \%, and EC:DEC (50:50) wt \%. Based on these mixtures, electrolytes based on lithium salts, $\mathrm{LiX}$ (with $\mathrm{X}=\mathrm{PF}_{6}^{-}$, or TFSI), were then prepared by dissolving a salt into the solvent and the concentrations of lithium salts in solutions are reported in $\mathrm{mol} \cdot \mathrm{dm}^{-3}$.

As the experimental setup used to determine the amount of $\mathrm{CO}_{2}$ dissolved in solutions is based on a chemical titration methodology, $\mathrm{NaOH}\left(0.5 \mathrm{~mol} \cdot \mathrm{dm}^{-3}\right)$ and $\mathrm{HCl}\left(1 \mathrm{~mol} \cdot \mathrm{dm}^{-3}\right)$ solutions, were used as received from Sigma Aldrich (Riedel-de Haen). Prior to any measurement, $\mathrm{HCl}\left(0.2 \mathrm{~mol} \cdot \mathrm{dm}^{-3}\right)$ solutions, which were prepared using double distilled water and the $\mathrm{HCl}\left(1 \mathrm{~mol} \cdot \mathrm{dm}^{-3}\right)$ commercial solution, were standardized from the $\mathrm{NaOH}$ commercial solution using potentiometric titration. Additionally, prior to any solubility measurement, solvents and electrolytes were analyzed for water content using 
coulometric Karl-Fischer (Coulometer 831 - Metrohm) titration. The water content of selected solvents and electrolytes, measured before and after their preparations, is close to $(10 \pm 1) 10^{-6}$.

The gases used (AGA/Linde Gaz) have the following specifications: carbon dioxide, mole fraction purity of 0.99995; and argon, mole fraction purity of 0.999997. All gases were used as received from the manufacturer. Information (i.e. source, abbreviation, purity, and water content) for each chemical sample studied in this paper are summarized in table 1.

\subsection{Experimental Methods}

The density of pure liquids, binary liquid mixtures and investigated electrolytes were measured by using a pycnometer $\left(5 \mathrm{~cm}^{3}\right)$ immersed in a water bath at $T=298.15 \mathrm{~K}$. The temperature control is ensured within $\pm 0.01 \mathrm{~K}$ by means of a JULABO thermostated bath. The pycnometer was firstly calibrated at $T=298.15 \mathrm{~K}$ with degassed water at atmospheric pressure using reference data from Wagner and Pruss [39]. More than three measurements were performed for each density measurement reported therein. The accuracy of the reported density values is better than $\pm 5 \times 10^{-2} \mathrm{~g} \cdot \mathrm{cm}^{-3}$.

The experimental apparatus used during the $\mathrm{CO}_{2}$ solubility measurements reported in this present work is based on a chemical titration technique, which was already described by our group elsewhere [22,23], and schematically represented herein in figure 1. Under a dry atmosphere in a glove box, a known quantity of electrolyte, determined gravimetrically with an accuracy of $\pm 1 \times 10^{-4} \mathrm{~g}$ using a Sartorius $1602 \mathrm{MP}$ balance, was first placed into equilibrium cell $(\mathrm{EqC})$ equipped with a septum to avoid air and moisture contaminations during measurements. The $\mathrm{EqC}$ was then immersed in a water bath maintained at constant temperature, $T_{\text {exp. }}$ using a PID temperature controller and accurately measured with a calibrated $100 \Omega$ platinum resistance thermometer within accuracy better than $\pm 0.1 \mathrm{~K}$. The electrolyte was then saturated with $\mathrm{CO}_{2}$ at atmospheric pressure by dissolving the gas in the liquid phase at constant temperature during 1 hour to reach the equilibrium. Furthermore, different equilibrium times were also examined to ensure that the saturation had been reached in each case. When the saturation was achieved an argon flow was used to displace the amount of 
dissolved $\mathrm{CO}_{2}$ in the solvent from the equilibrium cell to the titration cell, which contains a known concentration of $\mathrm{NaOH}$ aqueous solution. To ensure that a solventfree $\left(\mathrm{Ar}+\mathrm{CO}_{2}\right)$ gas mixture was introduced in the $\mathrm{NaOH}$ titration cell, the gas mixture was first passed through an ethanol bath at $T=193 \mathrm{~K}$, which retains the solvent from the gas stream. The displaced quantity of dissolved $\mathrm{CO}_{2}$ then reacts with $\mathrm{NaOH}$ solution by forming sodium carbonate (e.g. $\mathrm{Na}_{2} \mathrm{CO}_{3}$ ). The aqueous solution containing the sodium carbonate as well as the non-reacted $\mathrm{NaOH}$ was finally titrated by a known concentration of $\mathrm{HCl}$ solution, $C_{\mathrm{HCl}}$ as described in figure $\mathrm{S} 1$ of the supporting information, where, the first and second peaks correspond to the titrations of nonreacted $\mathrm{NaOH}$ and sodium carbonate, respectively. The difference of volumes between these two peaks, $\Delta V_{\mathrm{HCl}}$, calculated by using the derivative method of the $\mathrm{pH}$ with the respect to the $\mathrm{HCl}$ volume added, is directly link to the amount of dissolved $\mathrm{CO}_{2}$ in the solution, $n_{2}^{\text {liq }}$ :

$n_{2}^{\operatorname{liq}}=\Delta V_{\mathrm{HCl}} \cdot C_{\mathrm{HCl}}$

\subsection{Data analysis}

The solubility of the $\mathrm{CO}_{2}$ in studied solvent can be expressed in mole fraction of $\mathrm{CO}_{2}$ in solution, $x_{2}$ :

$$
x_{2}=\frac{n_{2}^{\text {liq }}}{n_{\text {solv }}^{\text {liq }}+n_{2}^{\text {liq }}}
$$

where $n_{2}^{\text {liq }}$ is the amount of $\mathrm{CO}_{2}$ dissolved in the liquid solution and $n_{\mathrm{solv}}^{\text {liq }}=n_{1}^{\text {liq }}+n_{3}^{\text {liq }}$ is the amount of solvent in the liquid phase introduced in the equilibrium cell, with $n_{1}^{\text {liq }}$ being the amount of alkylcarbonate solvents and $n_{3}^{\text {liq }}$ the amount of lithium salt in the liquid solution.

Henry's law constants can be then calculated from the $\mathrm{CO}_{2}$ mole fraction solubility as: 


$$
K_{\mathrm{H}}=\lim _{x_{2} \rightarrow 0} \frac{f_{2}\left(p, T, x_{2}\right)}{x_{2}} \approx \frac{\phi_{2}\left(p_{\text {exp. }}, T_{\text {exp. }}\right) p_{\text {exp. }}}{x_{2}}
$$

where $f_{2}$ is the fugacity of the $\mathrm{CO}_{2}$ and $\phi_{2}$ its fugacity coefficient calculated from the compilation of Dymond and Smith [40] at atmospheric pressure, $p_{\text {exp. and fixed }}$ temperature, $T_{\text {exp. }}$.

The determination of the solubility at different temperatures from (283 to 353$) \mathrm{K}$ is simply done by changing the water bath set point and by repeating the same saturation and titration procedures. Each measurement was run in triplicate to avoid any experimental error. To represent the $\mathrm{CO}_{2}$ solubility in selected solutions as a function of temperature, experimental data were then correlated in the whole temperature range by using the following empirical equation:

$$
\ln \left(\frac{K_{\mathrm{H}}(T)}{p^{0}}\right)=\sum_{i=0}^{n} A_{i}(T / \mathrm{K})^{-i}
$$

The coefficients $A_{i}$ obtained in the fit are reported in the whole manuscript together with the relative absolute average deviation, $R A A D$ obtained for each solute calculated as:

$$
R A A D=\frac{1}{N}\left|\frac{Y_{\text {expt. }}-Y_{\text {calcd. }}}{Y_{\text {calcd. }}}\right|=\frac{1}{N}|\delta|
$$

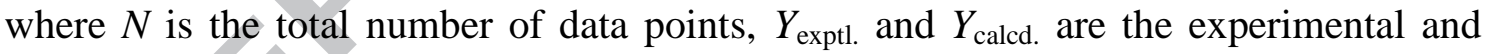
calculated data for the studied property, respectively. $\delta$ is the relative deviation between experimental and calculated data.

By using the equation 4, it is then possible to calculate the dissolution properties of the standard Gibbs energy, enthalpy and entropy of the dissolution of the $\mathrm{CO}_{2}$ in the solutions studied [41]:

$$
\Delta_{\mathrm{dis}} G^{0}=R T \ln \left(\frac{K_{\mathrm{H}}}{p^{0}}\right)
$$




$$
\begin{aligned}
& \Delta_{\text {dis }} H^{0}=-T^{2} \partial / \partial T\left(\frac{\Delta_{\text {dis }} G^{0}}{T}\right)=-R T^{2} \partial / \partial T\left[\ln \left(\frac{K_{\mathrm{H}}}{p}\right)\right] \\
& \Delta_{\text {dis }} S^{0}=\frac{\left(\Delta_{\text {dis }} H^{0}-\Delta_{\text {dis }} G^{0}\right)}{T}
\end{aligned}
$$

where $p^{0}$ is the standard state pressure.

Furthermore, the $\mathrm{CO}_{2}$ dissolution in solvents can be viewed as a two-step process involving an intermediate step, in which the $\mathrm{CO}_{2}$ is considered in its hypothetical liquid state driven by its standard enthalpy of liquefaction, $\Delta_{\text {liq }} H^{0}$.[22,41] Based on which, the enthalpy of mixing of the $\mathrm{CO}_{2}$ with solvent, $\Delta_{\text {mix }} H^{0}$, can be calculated as:

$$
\Delta_{\text {dis }} H^{0}=\Delta_{\text {liq }} H^{0}+\Delta_{\text {mix }} H^{0}
$$

where $\Delta_{\text {liq }} H^{0}=-16.90 \mathrm{~kJ} \cdot \mathrm{mol}^{-1}$ at $T=298.15 \mathrm{~K}$.[41] 


\subsection{COSMOThermX calculations}

The COSMOThermx software is based on the well known COSMO-RS (Conductor-like Screening Model for Real Solvent) methodology, which combines statistical thermodynamics methodology with the electrostatic theory of locally interacting molecular surface descriptors [42]. During this work, the same methodology as already presented previously by our group $[22,43]$ was used firstly to optimize each structure and then to calculate the $\mathrm{CO}_{2}$ solubility in selected solvents and mixtures, as well as in solutions containing additive salts like $\mathrm{LiPF}_{6}, \mathrm{LiFAP}$ or LiTFSI. Except, in the case of the calculations of the $\mathrm{CO}_{2}$ solubility in LiTFSI-based electrolytes as function of the lithium salt concentration - where different methodologies to define the sigma profile of the salt have been used, like ion pair, metafile or individual ions. All COSMOThermX calculations reported during this work were done by using the ion pair sigma profile generated for each lithium salt. The gas solubility calculations were realized by using the gas solubility option within the COSMOthermX program (version 2.1, release 01.06). In this method, the partial vapor pressure, and thus gas solubility, is estimated using the following equation:

$p_{(i)}=p_{o}{ }^{v a p}{ }_{(i)} x_{(i)} \gamma_{(i)}$

where $p_{(i)}, p_{o}{ }^{v a p}(i), x_{(i)}, g_{(i)}$ are the partial and pure vapour pressures, mole fraction and activity coefficient of a selected gaseous species $i$ in a particular solvent.[22]

During this investigation, each reported liquid composition describes the liquid phase used in the COSMOthermX software. Based on which, simulations were performed for each gas/liquid system under exactly the same conditions of temperature and pressure that were used in generating each experimental gas solubility data point. Each predicted value was determined from the simulation results as the mol fraction of gas in the liquid phase. 
3.1 Effect on the presence of Lithium salt on density and $\mathrm{CO}_{2}$ gas solubility in pure carbonate solvents.

Prior to determining the carbon dioxide solubility in electrolyte, the density of each solution was determined at $T=298.15 \mathrm{~K}$. Effect of the presence of $1 \mathrm{~mol} \cdot \mathrm{dm}^{-3}$ of $\mathrm{LiPF}_{6}$ or LiTFSI on the density values of investigated pure solvents is reported in table 2. As expected, the density of each solution containing a linear carbonate, such as DMC, EMC or DEC, decreases by increasing its alkyl chain length. Furthermore, each EC solution is denser than those containing a linear carbonate. Such conclusions are in agreement with those already reported into the literature.[44] The presence of $1 \mathrm{~mol} \cdot \mathrm{dm}^{-}$ ${ }^{3} \mathrm{LiPF}_{6}$ or LiTFSI dissolved into a pure solvent affects strongly the density of the solution. In each case, $\mathrm{LiPF}_{6}$ or LiTFSI electrolytes are denser than pure solvents. For examples, deviations up to (8.4 or 13.5$) \%$ on the density are observed by comparing the electrolyte density of $\left(\mathrm{DEC}+1 \mathrm{~mol} \cdot \mathrm{dm}^{-3} \mathrm{LiPF}_{6}\right.$ or LiTFSI) with that observed for the pure DEC solvent at $T=298.15 \mathrm{~K}$. It appears also that each electrolyte containing the LiTFSI salt is denser than that based on the $\mathrm{LiPF}_{6}$ salt. This conclusion is in agreement with that expected by comparing the effective molar volumes at $T=298.15$ $\mathrm{K}_{\text {of }} \mathrm{PF}_{6}^{-}\left(73.71 \mathrm{~cm}^{3} \cdot \mathrm{mol}^{-1}\right)$ and TFSI $\left(157.6 \mathrm{~cm}^{3} \cdot \mathrm{mol}^{-1}\right)$ anions [45]. Furthermore, nonaqueous solvents containing the $\mathrm{TFSI}^{-}$anion are generally denser than those based on the $\mathrm{PF}_{6}^{-}$[46],.Finally, from table 2, it appears also that calculated deviations between pure solvent and electrolyte density values are more important in the case of linear carbonates than those observed for cyclic compounds. Additionally, such deviations seem to increase with the alkyl chain length on the linear carbonate.

The experimental carbon dioxide solubility values among the eight selected electrolyte solutions containing $1 \mathrm{~mol} \cdot \mathrm{dm}^{-3} \mathrm{LiPF}_{6}$ or LiTFSI dissolved into a pure solvent (such as $\mathrm{EC}, \mathrm{DMC}, \mathrm{EMC}$ or DEC) are listed in table 3, where the solubility values are reported in terms of their $\mathrm{CO}_{2}$ mole fractions and Henry's law constants at atmospheric pressure. For each electrolyte studied, experimental data points were obtained within the temperature interval between (283 and 353) K, except in the case of the EC solutions 
where measurements were performed starting from $298.15 \mathrm{~K}$. Experimental results were then correlated by using the equation 4 to determine the effect of temperature on the $\mathrm{CO}_{2}$ solubility in each electrolyte. Fitting parameters and $R A A D$ (equation 5) are reported in each case in the table 4. According to Jacquemin et al. [47], the precision of the experimental values can be evaluated from the deviations between experimental values and those correlated by using equations 4 and 5 , which is herein lower than $2 \%$ except in the case of the $\mathrm{CO}_{2}$ solubility in EMC electrolytes.

Figure 2 represents the $\mathrm{CO}_{2}$ solubility data, expressed in mole fraction of $\mathrm{CO}_{2}$ (figure 2a) as well as in Henry's Law constants (figure 2b) at the atmospheric pressure, in the selected electrolyte containing $1 \mathrm{~mol} \cdot \mathrm{dm}^{-3} \mathrm{LiPF}_{6}$ or LiTFSI dissolved into pure solvents as a function of temperature. It is observed that whatever the anionic structure of the lithium salt dissolved in the pure solvent, the $\mathrm{CO}_{2}$ is more soluble in linear solvents than in the cyclic carbonate. That conclusion is in agreement with the variation already reported in the literature for the $\mathrm{CO}_{2}$ solubility in pure solvents [22-38]. From table 2 and figure 2, it can be also appreciated that, whatever the structure of the selected lithium salt dissolved in a pure solvent and whatever the temperature, the $\mathrm{CO}_{2}$ solubility increases in the following order: $\mathrm{EC}<\mathrm{DMC}<\mathrm{EMC} \leq \mathrm{DEC}$. For each electrolyte investigated, the $\mathrm{CO}_{2}$ solubility decreases with temperature. For example the $\mathrm{CO}_{2}$ solubility in EC and DEC electrolytes containing $1 \mathrm{~mol} \cdot \mathrm{dm}^{-3} \mathrm{LiPF}_{6}$ are close to $(0.0054$ and 0.0025) and to (0.0140 and 0.0055) in $\mathrm{CO}_{2}$ mole fraction units at $T=(298$ and 353) $\mathrm{K}$ and atmospheric pressure, respectively. Similarly, the $\mathrm{CO}_{2}$ solubility, under the same temperature and pressure conditions, in EC and DEC electrolytes containing $1 \mathrm{~mol} \cdot \mathrm{dm}^{-3}$ LiTFSI are close to (0.0056 and 0.0027) and to (0.0172 and 0.0081) in $\mathrm{CO}_{2}$ mole fraction units, respectively. In other words, the $\mathrm{CO}_{2}$ is slightly more soluble in electrolyte containing $1 \mathrm{~mol} \cdot \mathrm{dm}^{-3}$ LiTFSI than $1 \mathrm{~mol} \cdot \mathrm{dm}^{-3} \mathrm{LiPF}_{6}$. For example, at $T=$ 298.15 K the Henry's law constant of the $\mathrm{CO}_{2}$ in electrolyte based on the DMC and $1 \mathrm{f}$ $\mathrm{mol} \cdot \mathrm{dm}^{-3} \mathrm{LiPF}_{6}\left(\mathrm{~K}_{\mathrm{H}}=7.79 \mathrm{MPa}\right)$ is greater than that based on DMC and $1 \mathrm{~mol} \cdot \mathrm{dm}^{-3}$ LiTFSI $\left(K_{H}=6.20 \mathrm{MPa}\right)$, which reinforces the fact that the gas solubility in electrolyte is affected by the selection of the lithium salt dissolved in the solution. 
During a previous investigation, our group has reported a state-of-art experimental $\mathrm{CO}_{2}$ solubility in pure carbonate solvents as a function of temperature at $0.1 \mathrm{MPa}$ available in the literature [22] from which an accuracy close to $15 \%$ could be claimed even if our previous published values should be considered with accuracy close to $2 \%$. In the light of this conclusion, herein, we decided to compare experimental results of $\mathrm{CO}_{2}$ solubility in electrolytes presented in this work only with those previously reported by our group in the case of pure solvents (see table S1 of the supporting information),[22] in order to understand the effect of the addition of a lithium salt on the $\mathrm{CO}_{2}$ solubility in carbonate solutions. We report in figure 3 a comparison of the $\mathrm{CO}_{2}$ solubility in pure solvents and in different electrolytes containing $1 \mathrm{~mol} \cdot \mathrm{dm}^{-3} \mathrm{LiPF}_{6}$ or $1 \mathrm{~mol} \cdot \mathrm{dm}^{-3}$ LiTFSI at $T=$ 298.15 K (figure 3a) and 353.15 K (figure 3b). Based on this informaitoin, it appears that, the $\mathrm{CO}_{2}$ solubility is greater in pure solvents than in electrolytes containing 1 $\mathrm{mol} \cdot \mathrm{dm}^{-3} \mathrm{LiPF}_{6}$ over a temperature range from (293 to 353$) \mathrm{K}$. This observation is in agreement with COSMOThermX calculations done by our group previously [22], since a salting-out effect is experimentally observed by dissolving $1 \mathrm{~mol} \cdot \mathrm{dm}^{-3} \mathrm{LiPF}_{6}$ in all solvents investigated. On the other hand, the salting effect of the dissolution of 1 mol $\cdot \mathrm{dm}^{-3}$ LiTFSI in each solvent is more strongly affected by the structure of the selected solvent, as well as the interaction between solvent and TFSI $^{-}$anion. As reported herein by comparing data reported in tables 3 and S1 of the supporting information in the case of the $\mathrm{CO}_{2}$ solubility in each solution with or without the presence of $1 \mathrm{~mol} \cdot \mathrm{dm}^{-}$ ${ }^{3}$ LiTFSI salt (or see figure 3), no salting effect is observed by adding LiTFSI in EC, $a$ contrario of solutions based on the DMC and DEC from which salting-out and saltingin effects are, respectively, observed. Even if this effect depends mainly of both lithium salts and solvents structures and their interactions in solution, it appears also from the figure 3 that the temperature affects slightly the salting effect of each lithium salt in the solvents selected. For example, in the case of the EMC solutions salting-out and saltingin effects are observed by adding the LiTFSI at $T=(298$ and 353) K, respectively.

To analyze in detail these $\mathrm{CO}_{2}$ solubility results, we decided then to calculate the dissolution properties as well as the mixing enthalpy of the $\mathrm{CO}_{2}$ in these solutions at $T$ $=298.15 \mathrm{~K}$, which are reported herein in the table $\mathrm{S} 2$ of the supporting information and in table 5 in the case of the pure solvents and investigated electrolytes, respectively. As 
expected, the standard Gibbs energies of dissolution of $\mathrm{CO}_{2}$ in these solutions are positive, and follow the same order as that reported for the solubility, as the Gibbs energy is directly proportional to the logarithm of the Henry's law constants (see equation 6). Whatever the structures of the dissolved lithium salt or solvent used, the standard enthalpies and entropies of dissolution of $\mathrm{CO}_{2}$ in selected electrolytes are all negative, in other words the $\mathrm{CO}_{2}$ solubility in each electrolyte is entropy-driven and presents an exothermic process of dissolution. From table 5, it can be seen also that all enthalpies of mixing are positive, which clearly indicate the lack of specific interaction between selected electrolytes and $\mathrm{CO}_{2}$ especially in the case of electrolytes based on the DMC, which provide the lowest energy during the dissolution process. This conclusion reinforces that reported between pure solvents and $\mathrm{CO}_{2}$ [22]. Except in the case of the DEC, the difference observed between dissolution properties and mixing enthalpies of $\mathrm{CO}_{2}$ with pure solvents and with electrolytes containing $1 \mathrm{~mol} \cdot \mathrm{dm}^{-3} \mathrm{LiPF}_{6}$ or of LiTFSI reinforces the hypothesis that the presence of lithium salt affects the reorganization of the solution. For example, the presence of $1 \mathrm{~mol} \cdot \mathrm{dm}^{-3}$ lithium salt in EC solution decreases the entropy of dissolution at $T=298.15 \mathrm{~K}$ up to $20 \%$ in comparison with that observed in pure EC (see tables 5 and S2 of the supporting information), which can be linked to a better reorganization of the liquid phase in the presence of salt. Nevertheless, in the case of the linear carbonate, the presence of salt seems to increases slightly the mixing enthalpy (or the dissolution enthalpy) as well as the entropy of dissolution in the presence of $\mathrm{CO}_{2}$, driven by an increase of interaction and in fact of requested reorganization in solutions. In other words, linear and cyclic carbonates containing a lithium salt $\left(\mathrm{LiPF}_{6}\right.$ or LiTFSI) are probably driven by different molecular mechanisms of dissolution. By changing the salt dissolved in solution from $\mathrm{LiPF}_{6}$ to LiTFSI seems to increase the entropy of dissolution of $\mathrm{CO}_{2}$ in such electrolyte, again this conclusion can be linked to the structure differences between $\mathrm{PF}_{6}{ }^{-}$(spherical, symmetric with a charge density localized on the anion surface) and $\mathrm{TFSI}^{-}$anions (non-spherical and the charge on the anion surface is highly delocalized resulting in relatively weak cation-anion coulombic interactions) as shown in figure $\mathrm{S} 2$ of the supporting information. 
3.2 Effect on the presence of the lithium salt on density and $\mathrm{CO}_{2}$ gas solubility in binary mixture of carbonate solvents.

The density of binary mixtures of EC:DMC, EC:EMC, and EC:DEC (50:50) wt $\%$ at $T$ $=298.15 \mathrm{~K}$ is reported in table 6 , as well as density values measured in the case of electrolytes containing $1 \mathrm{~mol} \cdot \mathrm{dm}^{-3}$ lithium salt, e.g. $\mathrm{LiPF}_{6}, \mathrm{LiFAP}$ or LiTFSI. Density values from this table were then compared with those reported in table 2. As expected, each binary mixture of carbonate solvents has a density lower than that measured in the case of the pure EC and higher than those reported in the case of investigated linear carbonates. Furthermore, by increasing the alkyl chain length on the linear carbonate, the density of their mixtures with EC (50:50) wt \% decreases. Such conclusions are also observed in the case of electrolytes investigated. As shown in the previous section in the case of pure solvent, the presence of salt increases the density of the binary carbonate solution. From table 6, it appears also that the density of these electrolytes is also strongly affected by the structure of the selected anion, as we found that $\mathrm{FAP}^{-}$-based electrolytes are denser than $\mathrm{TFSI}^{-}$ones, which are denser that those based on the $\mathrm{PF}_{6}{ }^{-}$ anion. For example, in the case of the EC:DMC (50:50) wt \% electrolytes, density values close to $(1.34,1.29$ and 1.31$) \mathrm{g} \cdot \mathrm{cm}^{-3}$ are measured in the case of electrolyte containing $1 \mathrm{~mol} \cdot \mathrm{dm}^{-3} \mathrm{LiFAP}, \mathrm{LiPF}_{6}$, and LiTFSI salt, respectively. Again, this conclusion is in agreement with that expected by comparing the effective molar volumes at $T=298.15 \mathrm{~K}$ of $\mathrm{FAP}^{-}, \mathrm{PF}_{6}{ }^{-}$and TFSI..[45]

To evaluate the $\mathrm{CO}_{2}$ solubility changes by mixing a cyclic carbonate (EC) solvent with the linear molecule, the $\mathrm{CO}_{2}$ solubility in each (50:50) wt \% solution without salt, reported here in the table 7, was firstly determined from $T=(298$ to 353$) \mathrm{K}$ and compared to values obtained in the case of pure solvents (see table S1 and figure S3 of the supporting information). From this comparison, it appears that the presence of a cyclic carbonate solvent decreases strongly the $\mathrm{CO}_{2}$ solubility in solution containing a linear one. For example, at $T=298.15 \mathrm{~K}$ the $\mathrm{CO}_{2}$ solubility, expressed in $\mathrm{CO}_{2}$ mole fraction is close to $0.0057,0.0098,0.0104$ and 0.0118 in pure EC, EC:DMC, EC:EMC and EC:DEC (50:50) wt \% mixtures, respectively. While $x_{\mathrm{CO} 2}$ values close to 0.0136, 0.0170 , and 0.0165 are reported in the case of pure DMC, EMC and DEC, respectively 
[22]. In other words, at $T=298.15 \mathrm{~K}$, the $\mathrm{CO}_{2}$ solubility in carbonate solution increases in the following order: EC << EC:DMC (50:50) wt \% < EC:EMC (50:50) wt \% < EC:DEC (50:50) wt \% $<$ DMC $<$ DEC $<$ EMC. For each solution, its $\mathrm{CO}_{2}$ solubility decreases as a function of temperature, and for the covered temperature range, the $\mathrm{CO}_{2}$ solubility in selected mixtures are lower than those reported in pure linear carbonate solvents. Steric effects may explain the fact that $\mathrm{CO}_{2}$ is less soluble in mixtures of (EC + linear carbonate) than in pure linear solvents, driven also by the fact that $\mathrm{CO}_{2}$ solubility is lower in cyclic than in acyclic carbonates, as shown in figure S3 of the supporting information. This experimental observation is in agreement with that reported by Gui et al.[35] in the case of DMC:EC, DMC:PC and DMC:DEC mixtures. However, as this group has investigated the $\mathrm{CO}_{2}$ solubility in mixture based on a (1:1) volume ration, their results in the case of the EC:DMC mixture cannot be, directly, compared with those reported in this work. Nevertheless, at $T=298.15 \mathrm{~K}$ our group reports $x_{\mathrm{CO} 2}=0.0098$ in the case of the mixture based on EC:DMC (50:50 wt \%), such value is in agreement with that reported by Gui et al.[35], $x_{\mathrm{CO} 2}=0.0104$ at $T=298.15$ $\mathrm{K}$, in the case of the similar mixture based on a $(1: 1)$ volume ration.

The effect of the dissolution of $1 \mathrm{~mol} \cdot \mathrm{dm}^{-3} \mathrm{LiFAP}_{\mathrm{L}} \mathrm{LiPF}_{6}$, or LiTFSI salt in these binary carbonate mixtures on their $\mathrm{CO}_{2}$ solubility was then investigated as a function of the temperature. These experimental data are listed in the table 8, and shown in figure S4 of the supporting information. As expected, and shown in figure S4 of the supporting information, for each electrolyte investigated herein, the $\mathrm{CO}_{2}$ solubility decreases with temperature. Furthermore, a comparison of the $\mathrm{CO}_{2}$ solubility data reported in each selected mixture in absence (table 7) or in presence of a lithium salt (table 8) shows, as expected from the previous section, a strong effect of the salt on this property. As shown in figure 4 , it appears that, the $\mathrm{CO}_{2}$ solubility is higher in binary carbonate mixtures than in electrolytes containing $1 \mathrm{~mol} \cdot \mathrm{dm}^{-3} \mathrm{LiPF}_{6}$ for a temperature range from (293 to 353$) \mathrm{K}$. For example, at $T=298.15 \mathrm{~K}$ a decrease up to $(20.4,19.8$ and 25.4$) \%$ on the $\mathrm{CO}_{2}$ solubility in solution containing $1 \mathrm{~mol} \cdot \mathrm{dm}^{-3} \mathrm{LiPF}_{6}$ is observed in comparison with solubility values obtained in the absence of salt in the case of EC:DMC, EC:EMC and EC:DEC (50:50) wt \% mixtures, respectively. Nevertheless, each solubility decrease is generally less pronounced by increasing the temperature, since the $\mathrm{CO}_{2}$ 
solubility in the absence of salt in the case of EC:DMC and EC:EMC (50:50) wt \% mixtures are (11.9 and 15.9) \% higher than in presence of $1 \mathrm{~mol} \cdot \mathrm{dm}^{-3} \mathrm{LiPF}_{6}$. In other words, the temperature seems to affect differently the $\mathrm{CO}_{2}$ solubility in these electrolytes but for each investigated temperature $\mathrm{LiPF}_{6}$ salt has a salting-out effect on the $\mathrm{CO}_{2}$ solubility in carbonate mixtures. By substituting the $\mathrm{LiPF}_{6}$ by the LiTFSI salt, it appears that the $\mathrm{CO}_{2}$ solubility in each solution increases. For example, at $T=298.15 \mathrm{~K}$ the $\mathrm{CO}_{2}$ solubility, expressed in $\mathrm{CO}_{2}$ mole fraction unit, in EC:DMC, EC:EMC and EC:DEC (50:50) wt \% electrolytes containing $1 \mathrm{~mol} \cdot \mathrm{dm}^{-3}$ LiTFSI are close to $(0.0098$, 0.0106 and 0.0125 ), and are higher than those observed in electrolytes containing 1 $\mathrm{mol} \cdot \mathrm{dm}^{-3} \mathrm{LiPF}_{6}$ (e.g. $0.0085,0.0087$ and 0.0088 ), respectively. By comparing such solubility values with those measured in the case of the absence of salt, it appears that at $T=298.15 \mathrm{~K}$ no salting effect is observed by adding LiTFSI in EC:DMC (50:50) wt \% mixture, while salting-in effects are observed in EC:EMC and EC:DEC (50:50) wt \% mixtures. As reported in the previous section and shown in figure 4, the temperature affects slightly the salting effect of LiTFSI salt in the selected carbonate mixtures. For example, in the case of the EC:EMC and EC:DEC (50:50) wt \% solutions salting-in and salting-out effects are observed by adding the LiTFSI at $T=(298$ and 353) $\mathrm{K}$, respectively. At $T=298.15 \mathrm{~K}$, in the case of the LiFAP electrolytes, no salting effect is observed in EC:DMC (50:50) wt \% mixture, while again, salting-in effects are observed in EC:EMC and EC:DEC (50:50) wt \% mixtures. As reported in the case of the LiTFSI, these salting effects depend on the structure of solvents involved in the mixture, as well as on the temperature, as depicted from tables 7 and 8 and shown in figure 4 . Nevertheless, from figure 4 and table 8 , it can be also appreciated that the $\mathrm{CO}_{2}$ is, generally, slightly more soluble in electrolyte containing $1 \mathrm{~mol} \cdot \mathrm{dm}^{-3}$ LiFAP than 1 mol $\cdot \mathrm{dm}^{-3}$ LiTFSI. For example, at $T=298.15 \mathrm{~K}$ the Henry's law constant of the $\mathrm{CO}_{2}$ in electrolyte based on the EC:DEC (50:50) wt $\%$ mixture and $1 \mathrm{~mol} \cdot \mathrm{dm}^{-3} \mathrm{LiFAP}\left(\mathrm{K}_{\mathrm{H}}=\right.$ $6.37 \mathrm{MPa}$ ) is lower than that based on EC:DEC (50:50) wt \% mixture and $1 \mathrm{~mol} \cdot \mathrm{dm}^{-3}$ LiTFSI $\left(\mathrm{K}_{\mathrm{H}}=8.00 \mathrm{MPa}\right)$, which reinforces again that the gas solubility in the electrolyte is strongly affected by the selection of the lithium salt dissolved in the solution. On the other hand, it appears from this work that the $\mathrm{CO}_{2}$ solubility in selected electrolytes increases in the following order: $\mathrm{LiPF}_{6}<\mathrm{LiTFSI} \leq \mathrm{LiFAP}$. This solubility trend can be 
explained by the difference of their volumes and sigma profiles (charge density on each anion surface) as reported in figure $\mathrm{S} 2$ of the supporting information.

In order to assess the dissolution properties, as well as the mixing enthalpy of $\mathrm{CO}_{2}$ with each binary carbonate mixture in the absence or in the presence of $1 \mathrm{~mol} \cdot \mathrm{dm}^{-3}$ lithium salt $\left(\mathrm{LiPF}_{6}, \mathrm{LiTFSI}\right.$ or LiFAP), the variation of their $\mathrm{CO}_{2}$ solubility was then first adjusted by using the equation 4 as a function of temperature. Best fitting parameters along their $R A A D$ with experimental data are reported in table 9. From this table, it appears that all RAAD are lower than $2 \%$, except for mixtures based on EC:DMC + 1 $\mathrm{mol} \cdot \mathrm{dm}^{-3} \mathrm{LiPF}_{6}, \mathrm{EC}: \mathrm{EMC}+1 \mathrm{~mol} \cdot \mathrm{dm}^{-3} \mathrm{LiFAP}$ and EC:DEC $+1 \mathrm{~mol} \cdot \mathrm{dm}^{-3} \mathrm{LiFAP}$, where $R A A D$ close to $(2.7,3.1$ and 3.3$) \%$ were observed. Based on these fitting parameters, dissolution properties and mixing enthalpy of $\mathrm{CO}_{2}$ with these solutions are then calculated and reported herein in table 10 at $T=298.15 \mathrm{~K}$. Whatever the dissolved lithium salt or the selected mixture, the standard enthalpies and entropies of dissolution of $\mathrm{CO}_{2}$ in selected binary mixtures and in electrolytes are all negative. As observed in the previous section, the $\mathrm{CO}_{2}$ solubility in each solution is entropy-driven and presents an exothermic process of dissolution. From the table 10 and its comparison with table S2 of the supporting information, it appears that in the absence of salt, all (50:50) wt \% carbonate binary mixtures have dissolution properties at $T=298.15 \mathrm{~K}$ lower than those observed in the case of the pure EC, but generally higher than those expected in pure linear carbonates. For example, at $T=298.15 \mathrm{~K}$, the entropy of dissolution of $\mathrm{CO}_{2}$ in these solutions increases following this order: DMC $<$ EC:DMC (50:50) wt \% $<$ EMC $<$ EC:EMC (50:50) wt \% < EC:DEC (50:50) wt $\%<$ DEC < EC. The reorganization of the liquid phase in the presence of $\mathrm{CO}_{2}$ is in fact affected by the nature and structure of each component that defines the liquid phase. The interactions in solution also depend on such factors, since the enthalpy of dissolution, as well as the mixing enthalpy of $\mathrm{CO}_{2}$ in all (50:50) wt \% carbonate binary mixtures, is lower than those observed in the case of pure EC. From table 10, it also appears that whatever mixture is selected, all mixing enthalpies are positive, which indicates the lack of specific interaction between $\mathrm{CO}_{2}$ and each solution. By adding a salt, a similar conclusion can be made, even if the presence of $\mathrm{LiPF}_{6}$ increases the mixing enthalpy values of $\mathrm{CO}_{2}$ and solutions, a contrario of LiTFSI or LiFAP ones. This trend can be linked to the salting effect of these lithium 
salts on the $\mathrm{CO}_{2}$ solubility in solution. The entropy of dissolution of $\mathrm{CO}_{2}$ and solution seems also to be slightly affected by the presence and the structure of lithium salts. For each electrolyte investigated, the presence of the salt increases the entropy of dissolution of $\mathrm{CO}_{2}$ and electrolyte following this order: $\mathrm{LiPF}_{6}<\mathrm{LiFAP}<$ LiTFSI. For example at $T=298.15 \mathrm{~K}$, entropy values up to $(-76,-78,-85$ and -82$) \mathrm{J} \cdot \mathrm{K}^{-1} \cdot \mathrm{mol}^{-1}$ are observed in the case of the (50:50) wt \% EC:DEC mixture with no salt or containing 1 $\mathrm{mol} \cdot \mathrm{dm}^{-3} \mathrm{LiPF}_{6}$, LiTFSI and LiFAP, respectively. This increase of entropy can be associated by a better reorganization of the liquid phase in the presence of lithium salt.

As each $\mathrm{CO}_{2}$ solubility process is entropy driven and as the presence of lithium salt affects this property as well as the solubility of $\mathrm{CO}_{2}$ in solution, we decided to investigate in greater detail the effect of the salt concentration on the $\mathrm{CO}_{2}$ solubility in the electrolyte. During this work, we selected the EC:DMC (50:50) wt \% mixture as a probe to identify this effect by increasing the $\mathrm{LiPF}_{6}$ or LiTFSI salt concentration in solution at $T=298.15 \mathrm{~K}$. The $\mathrm{CO}_{2}$ solubility in both electrolytes was then investigated as a function of the lithium salt concentration at $298.15 \mathrm{~K}$ and then compared with that observed in the EC:DMC (50:50) wt \% mixture without salt. These experimental values are listed in the table $\mathrm{S} 3$ of the supporting information and shown in figure 5. From this figure, it can be observed that at $T=298.15 \mathrm{~K}$ the $\mathrm{CO}_{2}$ solubility in $\mathrm{LiPF}_{6}$ decreases mostly linearly with the salt concentration in solution. Furthermore, as this electrolyte has a lower $\mathrm{CO}_{2}$ solubility than the EC:DMC (50:50) wt \% mixture without salt, it can be concluded that whatever the salt concentration in solution, a salting-out effect is observed in the case of the dissolution of $\mathrm{LiPF}_{6}$ in this solution. Nevertheless, from our investigation no trivial trend can be dressed in the case of the LiTFSI-based electrolyte (Figure 5). Surprisingly, at $T=298.15 \mathrm{~K}$, a minimum $\mathrm{CO}_{2}$ solubility in this electrolyte is observed as a function of the salt concentration for a lithium composition close to 2 mol $\cdot \mathrm{dm}^{-3}$. The $\mathrm{CO}_{2}$ solubility in this electrolyte decreases up to this lithium concentration and then seems to increase again. By comparing these solubility results with those obtained in the case of EC:DMC (50:50) wt \% mixture without salt, it appears, as shown in figure 5 , that for LiTFSI concentration in solution between ( 1 and 3) $\mathrm{mol} \cdot \mathrm{dm}^{-3}$ a salting-out effect is observed by dissolving LiTFSI in this solution. However, for the LiTFSI concentration in solution lower than $1 \mathrm{~mol} \cdot \mathrm{dm}^{-3}$ a salting-in 
effect is observed. This result demonstrates again that no-trivial conclusion about salting effects as well as solubility trends can be addressed, but reinforces the fact that the $\mathrm{CO}_{2}$ solubility in electrolytes is mainly driven by the temperature, pressure, and the formulation of the electrolyte through the selection of carbonate mixture, structure and concentration of lithium salt dissolved in solution.

\subsection{Evaluation of the $\mathrm{CO}_{2}$ solubility prediction in electrolytes using COSMOthermX.}

In the light of the structural and charge density differences between the $\mathrm{FAP}^{-}, \mathrm{PF}_{6}{ }^{-}$and TFSI $^{-}$anions (see figure S2 of the supporting information) as well as in order to evaluate different tools able to predict the gas solubility in Li-ion electrolytes, experimental results presented herein were then compared with those calculated by COSMOthermX by using the same methodology reported by our group previously.[22] Additionally, we decided to investigate, herein, the accuracy of the COSMO-RS method in the case of the $\mathrm{CO}_{2}$ solubility in electrolytes as a function of the temperature from (298 to 353) $\mathrm{K}$ by comparing the $\mathrm{CO}_{2}$ solubility in electrolytes calculated by COSMOthermX with all experimental data presented during this work.

Firstly, we reported in table S1 of the supporting information the COSMOThermX calculation of the $\mathrm{CO}_{2}$ solubility in pure solvents as a function of temperature from (298 to 353) K, as well as their comparisons with experimental results reported previously [22]. From this table, it appears that COSMOThermX is able to predict the $\mathrm{CO}_{2}$ solubility in pure solvents within accuracy up to $28 \%$. However, this methodology seems to be unable to predict the $\mathrm{CO}_{2}$ solubility order observed experimentally. For example, COSMOThermX predicts a higher $\mathrm{CO}_{2}$ solubility in DEC than in EMC. However, in each case, the $\mathrm{CO}_{2}$ solubility in pure solvents is calculated with the respect of the order of magnitude giving in fact the possibility to screen the $\mathrm{CO}_{2}$ solubility using COSMOThermX prior to experimental measurements, not only at $T=298.15 \mathrm{~K}$ as reported previously by our group [22], but also as a function of temperature. Secondly, an evaluation of the $\mathrm{CO}_{2}$ solubility prediction in the selected (50:50) wt \% binary mixtures like EC:DMC, EC:EMC and EC:DEC using COSMOThermX has been then realized as a function of temperature as reported in table S4 of the supporting 
information. From this information, it appears that the methodology is able to predict not only the order of magnitude of the reported $\mathrm{CO}_{2}$ solubility in these binary mixtures but also the $\mathrm{CO}_{2}$ solubility order observed experimentally: e.g. EC:DMC (50:50) wt \% $<$ EC:EMC (50:50) wt \% < EC:DEC (50:50) wt \% within an accuracy close to $35 \%$. This result is in agreement with those already reported by our group [22] and by Kolar et al. [44]. It appears also from the table $\mathrm{S} 4$ of the supporting information that $\mathrm{CO}_{2}$ gas solubility in binary carbonate mixture are over estimated by COSMOThermX, but also that each difference between calculated and experimental results decreases by increasing the temperature.

After these evaluations on the COSMOThermX predictability of the $\mathrm{CO}_{2}$ solubility in solution without lithium salt as a function of temperature, COSMOThermX calculations were performed to estimate the effect of the dissolution of $1 \mathrm{~mol} \cdot \mathrm{dm}^{-3}$ lithium salt $\left(\mathrm{LiPF}_{6}\right.$, LiFAP or LiTFSI) in each solution described during the experimental part, on the $\mathrm{CO}_{2}$ solubility as a function of temperature as reported in the table S5 of the supporting information. As depicted from this table and shown in figure 6, excellent agreements were obtained between calculations and experimental data sets in the case of the EC $+1 \mathrm{~mol} \cdot \mathrm{dm}^{-3} \mathrm{LiPF}_{6}$ and $\mathrm{EC}+1 \mathrm{~mol} \cdot \mathrm{dm}^{-3}$ LiTFSI electrolytes as a function of temperature with deviations up to (3.4 and 6.4) \%, respectively. Nevertheless, for the other electrolytes investigated greater deviations between COSMOThermX calculations and experimental data sets were found as shown in the case of some LiTFSI-based electrolytes in figure 7. For example, deviations close to (45 and 30) \% are obtained in the case of the DEC $+1 \mathrm{~mol} \cdot \mathrm{dm}^{-3} \mathrm{LiPF}_{6}$ and DEC $+1 \mathrm{~mol} \cdot \mathrm{dm}^{-3}$ LiTFSI electrolytes, respectively. For a temperature range from (298 to 353$) \mathrm{K}$, the overall accuracy of the COSMOThermX calculation is close to (40,33 and 39) \% in the case of $\mathrm{LiPF}_{6}$, LiTFSI and LiFAP electrolytes, respectively. This accuracy is in agreement with those already claimed by our group in the case of $\mathrm{CO}_{2}$ solubility in pure carbonate solvents at $T=$ $298.15 \mathrm{~K}$ [22], as well as in pure ionic liquids as a function of temperature [43].

Furthermore, as expected from the structural and charge density differences observed between each individual selected anion (see figure S2 of the supporting information), COSMOThermX calculations predict accurately that the $\mathrm{CO}_{2}$ solubility in electrolyte 
depends of the anion structure, as reported in the figure 8. Additionally, it appears from this work that COSMOThermX is able to reproduce accurately the experimental observation that the $\mathrm{CO}_{2}$ solubility in selected electrolytes increases in the following order: $\mathrm{LiPF}_{6}<\mathrm{LiTFSI} \leq \mathrm{LiFAP}$. Nevertheless, even if COSMOThermX reproduces correctly the salting-out effect in the case of the $\mathrm{LiPF}_{6}$, experimental observations in the case of the LiTFSI and LiFAP salts are not correctly predicted by using this method. For example, in the case of the EC:EMC and EC:DEC (50:50) wt \% solutions salting-in and salting-out effects are experimentally observed by adding the LiTFSI at $T=(298$ and 353) K, respectively ; while COSMOThermX calculations show a salting-out effect in each case. Additionally, a salting-in effect is expected from COSMOThermX calculation by adding LiFAP salt in each solution, while salting-in and salting-out effects are experimentally observed depending of the selected carbonate mixture and temperature.

To evaluate in greater detail the $\mathrm{CO}_{2}$ gas solubility prediction in electrolytes by COSMOThermX, calculations were then carried-out as a function of the lithium salt concentration in solution and then compared with experimental data sets as reported in table S6 of supporting information and shown in figure 8. In the light of the incorrect prediction of the salting effect in the case of the LiTFSI, we decided then to perform our calculations by using different "cosmo files" to define this lithium salt. During this study, three different calculation methodologies were used by defining the LiTFSI as an ion pair (i.e. as for the other calculations), or as two individual ions (by using two separated "cosmo files", one per ion, by using a similar calculation approach as reported by our group previously in the case of ionic liquid [43]), or as a metafile based on a binary mixture "cosmo file" containing each ion at the 1:1 mol ratio created using the metafile editor option within COSMOThermX. From the figure 9 and the table S6 of the supporting information, it appears that COSMOThermX is able to reproduce the decrease of the $\mathrm{CO}_{2}$ solubility in $\mathrm{LiPF}_{6}$-based electrolytes as a function of the salt concentration within accuracy close to $55 \%$. In the case of LiTFSI salt, by using the same methodology as before, i.e. by defining the LiTFSI as an ion-pair file during calculations, COSMOThermX predicts an increase of the $\mathrm{CO}_{2}$ solubility in such electrolyte as the function of the salt concentration in solution. Furthermore, for LiTFSI 
concentration lower or higher than $1 \mathrm{~mol} \cdot \mathrm{dm}^{-3}$ a salting-out or salting-in effect is predicted by using this tool. Nevertheless, both observations are not in agreement with the experimental values as shown by comparing figure 5 (experimental) with the Figure 9 (COSMOThermX calculations). By using metafile or individual ions "cosmo files" to define the LiTFSI salt, minima of the $\mathrm{CO}_{2}$ solubility in these electrolytes are observed for a lithium concentration close to $(2$ or 1.5$) \mathrm{mol} \cdot \mathrm{dm}^{-3}$, respectively. Even if this solubility trend as a function of the lithium salt concentration in solution is observed experimentally, both calculation methods predict a salting-out effect for this salt, as well as $\mathrm{CO}_{2}$ solubility in LiTFSI-based electrolytes lower than in the cases of $\mathrm{LiPF}_{6}$. In other words, COSMOThermX is unable to reproduce quantitatively all observations from experimental values even by using different strategy to define the lithium salt within COSMOThermX. However this method provides qualitative answers such as the good order of magnitude of the $\mathrm{CO}_{2}$ solubility in electrolytes as a function of temperature, the correct solubility trends as a function of the solvent or lithium salt structures within an overall uncertainty close to $35 \%$. Finally, from our investigations by defining the lithium salt as an ion pair during the COSMOThermX calculations, a better description of experimental data is obtained while experimentally for such concentrations (e.g. lower than $3 \mathrm{~mol} \cdot \mathrm{dm}^{-3}$ ) in solution we can expect a salt dissociation. 


\section{Conclusions}

We report firstly in this study the solubility of carbon dioxide in different electrolytes containing $1 \mathrm{~mol} \cdot \mathrm{dm}^{-3}$ lithium salt, $\mathrm{LiPF}_{6}$ or LiTFSI, dissolved in a pure alkylcarbonate solvent namely EC, DMC, EMC, DEC as a function of temperature from (283 to 353) $\mathrm{K}$ and atmospheric pressure. We have then compared these results with those previously reported by our group in the case of pure solvents in order to understand the effect of the addition of a lithium salt on the $\mathrm{CO}_{2}$ solubility in carbonate solutions.

In the second part of this study, we present $\mathrm{CO}_{2}$ solubility in binary mixtures of EC:DMC, EC:EMC, and EC:DEC (50:50) wt \% containing $1 \mathrm{~mol} \cdot \mathrm{dm}^{-3}$ lithium salt, e.g. $\mathrm{LiPF}_{6}, \mathrm{LiFAP}$ or LiTFSI at $T=298.15 \mathrm{~K}$ and atmospheric pressure. It appears from this work that the $\mathrm{CO}_{2}$ solubility increases in the following order: $\mathrm{LiPF}_{6}<\mathrm{LiTFSI} \leq \mathrm{LiFAP}$, which can be explained by the difference of their volumes and sigma profiles.

From these experimental values, whatever the temperature and selected carbonate solvent or mixture, a clear salting out effect is observed in the case of the dissolution of $\mathrm{LiPF}_{6}$ salt in each selected solution. In the case of LiTFSI or LiFAP, no salting, salting in or salting out effects are observed depending of the temperature, or structure of the carbonate solution. From this work, it appears that the salting effect depends mainly on both lithium salt and solvent structures and their interactions in solution. From the variation of $\mathrm{CO}_{2}$ solubility with temperature, the parameters, dissolution properties and mixing enthalpy of $\mathrm{CO}_{2}$ with these solutions are calculated showing that the $\mathrm{CO}_{2}$ solubility in each solution is entropy-driven and present an exothermic process of dissolution.

Finally, from our investigations by defining the lithium salt as an ion pair during the COSMOThermX calculations, a better description of experimental data is obtained while experimentally for investigated concentrations in solution we can expect a salt dissociation. These results and analysis presented herein can drive the formulation of safer electrolytes based on the dissolution of lithium salt in alkylcarbonates for lithium ion batteries.

Acknowledgement. The authors would like to thank Saft for providing funding support for this work. 


\section{Supplementary data}

Additional Supporting Information includes a description of the $\mathrm{pH}$ titration of dissolved $\mathrm{CO}_{2}$ in a solvent; variation of the $\mathrm{CO}_{2}$ solubility in the case of binary carbonates mixtures in absence or presence of a lithium salt as a function of temperature; sigma profile of selected anions; $\mathrm{CO}_{2}$ solubility data calculated using COSMOThermX as a function of electrolyte and temperature, as well as their comparisons with experimental data reported into this work. This material is available free of charge via the Internet at http://www.sciencedirect.com. 


\section{References}

[1] J.M. Tarascon, M. Armand, Nature 414 (2001) 359-367.

[2] Z. Chen, W.Q. Lu, J. Liu, K. Amine, Electrochim. Acta. 51 (2006) 3322-3326.

[3] D. Aurbach, Y. Talyosef, B. Markovsky, E. Markevich, E. Zinigrad, L. Asraf, S.J. Gnanaraj, H.-J. Kim, Electrochim. Acta. 50 (2004) 247-254.

[4] H. Wang, M. Yoshio, A.K. Thapa, H. Nakamura, J. Power Sources. 169 (2007) 375-380.

[5] M. Dahbi, F. Ghamouss, F. Tran-Van, D. Lemordant, M. Anouti, J. Power Sources 196 (2011) 9743-9750.

[6] J.S. Gnanaraj, M.D. Levi, Y. Gofer, D. Aurbach, M. Schmidt, J. Electrochem. Soc. 150 (2003) A445-A454.

[7] D. Aurbach, B. Markovsky, A. Schechter, Y. Ein-Eli, H. Cohen, J. Electrochem. Soc. 143 (1996) 3809-3820.

[8] C. Jung, Solid State Ionics 179 (2008) 1717-1720.

[9] M.C. Smart, B.V. Ratnakumar, L.D. Whicanack, K.A. Smith, S. Santee, F.J. Puglia, R. Gitzendanner, ECS Trans. 25 (2010) 273-282.

[10] S. Sylla, J.Y. Sanchez, M. Armand, Electrochim. Acta 37 (1992) 1699-1701.

[11] H.-B. Han, S.-S. Zhou, D.-J. Zhang, S.-W. Feng, L.-F. Li, K. Liu, W.-F. Feng, J. Nie, H. Li, X.-J. Huang, M. Armand, Z.-B. Zhou, J. Power Sources 196 (2011) 3623-3632.

[12] B. Garcia, M. Armand, J. Power Sources 132 (2004) 206-208.

[13] A. Abouimrane, J. Ding, I. Davidson, J. Power Sources. 189 (2009) 693-696.

[14] J.L. Krause, W. Lamanna, J. Summerfield, M. Engle, G. Korba, R. Loch, R. Atanasoski, J. Power Sources. 68 (1997) 320-325.

[15] M. Ue, A. Murakami, S. Nakamura, J. Electrochem. Soc. 149 (2002), A1572A1577.

[16] M. Arakawa, J.-I. Yamaki, J. Power Sources 54 (1995) 250-254.

[17] M. Ue, M. Takeda, M. Takehara, S. Mori, J. Electrochem. Soc. 144 (1997) 26842688.

[18] S.A. Freunberger, Y. Chen, Z. Peng, J.M. Griffin, L.J. Hardwick, F. Bardé, P. Novak, P.G. Bruce, J. Am. Chem. Soc. 133 (2011) 8040-8047. 
[19] S.A. Freunberger, Y. Chen, N.E. Drewett, L.J. Hardwick, F. Bardé, P.G. Bruce, Angew. Chem. 50 (2011) 8609-8613.

[20] M. Moshkovich, M.J. Cojocaru, H.E. Gottlieb, D. Aurbach, J. Electroanal. Chem. 497 (2001) 84-96.

[21] F Joho, P Novak, Electrochim. Acta 45 (2000) 3589-3599.

[22] M. Anouti, Y.R. Dougassa, C. Tessier, L. El Ouatani, J. Jacquemin, J. Chem. Thermodyn. 50 (2012) 71-79.

[23] F. Blanchard, B. Carré, F. Bonhomme, P. Biensan, D. Lemordant, Can. J. Chem. 81 (2003) 385-391.

[24] P.D. Mantor, O. Abib, K.Y. Song, R. Kobayashi, J. Chem. Eng. Data 27 (1982) 243-245.

[25] E.E. Issac, F.D. Otto, A.E. Mather, Can. Chem. Eng. J. 55 (1977) 751-752.

[26] Y.P. Zubchenko, S.F. Shakhova, T. Wei, L.I. Titelman, L.K. Kaplan, Zh. Prikl. Khim. 44 (1971) 2044-2047.

[27] O.R. Rivas, J.M. Prausnitz, AIChE J. 25 (1979) 975-984.

[28] L. Hongling, Z. Rongjiao, X. Wei, L. Yanfen, S. Yongju, T. Yiling, J. Chem. Eng. Data 56 (2011) 1148-1157.

[29] J.Y. Lenoir, P. Renault, H. Renon, J. Chem. Eng. Data 16 (1971) 340-342.

[30] F. Murrieta-Guevara, A.T. Rodriguez, J. Chem. Eng. Data 29 (1984) 456-460.

[31] F. Murrieta-Guevara, A.R. Martinez, A.T. Rodriguez, Fluid Phase Equilibr. 44 (1988) 105-115.

[32] Y. Xu, R. P. Schutte, L. G. Hepler, Can. Chem. Eng. J. 70 (1992) 569-573.

[33] P. Schmack, H.J. Bittrich, In Gas purification, A.L. Kohl, F.C. Riesenfeld (Eds), 2nd ed., Chapter 14, Gulf Publishing Co., Houston, 1974.

[34] D.M. Kassim, H.A. Zainel, S.A. Al-Asaf, E.K. Talib, Fluid Phase Equilibr. 41 (1988) 287-294.

[35] X. Gui, Z. Tang, W. Fei, J. Chem. Eng. Data 55 (2010) 3736-3741.

[36] R. Vilcu, S.T. Perisanu, M. Cucuiat, Pol. J. Chem. 54 (1980) 2043-2050.

[37] S.T. Perisanu, J. Solution Chem. 30 (2001) 183-192.

[38] X. Gui, Z. Tang, W. Fei, Low Carbon Economy 2 (2011) 26-31.

[39] W. Wagner, A. Pruss, J. Phys. Chem. Ref. Data 31 (2002) 387-535. 
[40] J.H. Dymond, E.B. Smith, The Virial Coefficients of Pure Gases and Mixtures, Clarendon Press, Oxford, 1980.

[41] J.H. Hildebrand, J.M. Prausnitz, R.L. Scott, Regular and Related Solutions, Van Nostrand Reinhold, New York, 1970, pp 111-141.

[42] F. Eckert, A. Klamt, COSMOtherm User's Manual: Version C2.1, Release 01.06 2006, COSMOlogic GmbH \& Co. KG, Leverkusen, Germany.

[43] N. Ab Manan, C. Hardacre, J. Jacquemin, D.W. Rooney, T.G.A. Youngs, J. Chem. Eng. Data 54 (2009) 2005-2022.

[44] P. Kolar, H. Nakata, J.-W. Shen, A. Tsuboi, H. Suzuki, M. Ue, Fluid Phase Equilibr. 228-229 (2005) 59-66.

[45] J. Jacquemin, R. Ge, P. Nancarrow, D.W. Rooney, M.F. Costa Gomes, A.A.H. Padua, C. Hardacre, J. Chem. Eng. Data 53 (2008) 716-726.

[46] D.W. Rooney, J. Jacquemin, R. Gardas, Top. Curr. Chem. 290 (2009) 185-212.

[47] J. Jacquemin, M.F. Costa Gomes, P. Husson, V. Majer, J. Chem. Thermodyn. 38 (2006) 490-502. 
Figure 1. Solubility equipment used in this work: EqC, equilibrium cell containing the $\mathrm{CO}_{2}$ saturated solvent; $\mathrm{TC}$, titration cell containing the $\mathrm{NaOH}$ aqueous solution.[22]

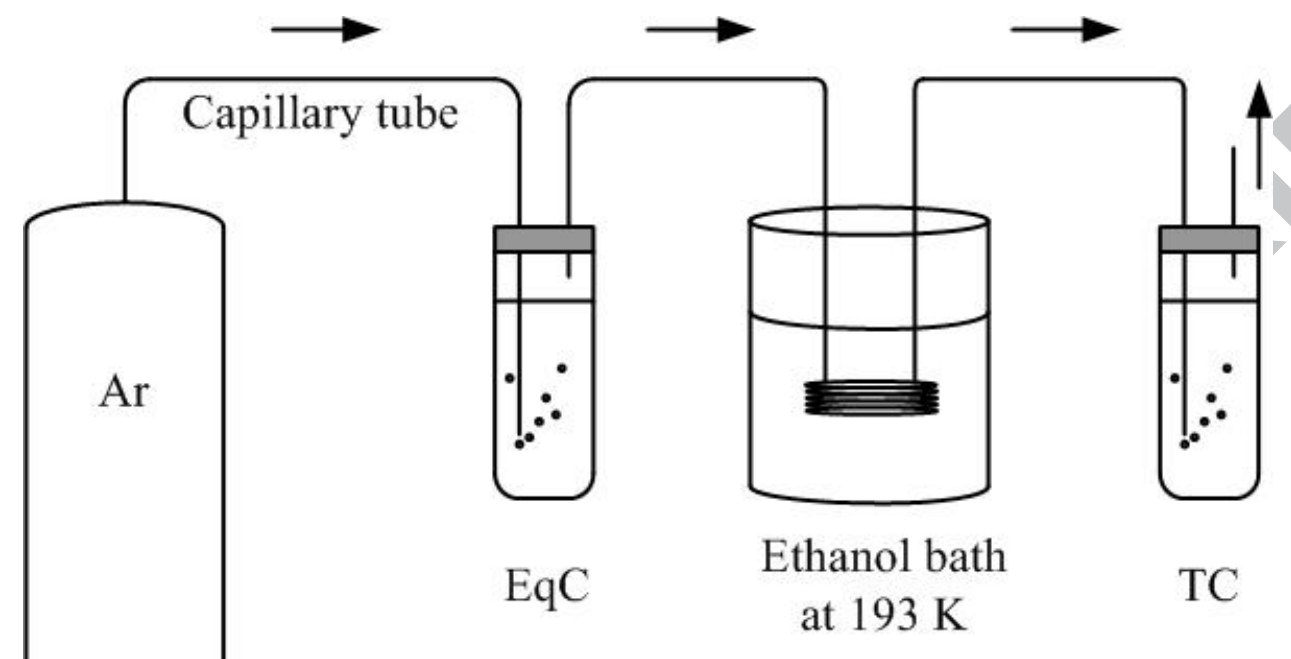


Figure 2. $\mathrm{CO}_{2}$ solubility as a function of temperature in: $\mathrm{EC}+1 \mathrm{~mol} \cdot \mathrm{dm}^{-3} \mathrm{LiPF}_{6} ; \mathrm{O}$, $\mathrm{EC}+1 \mathrm{~mol} \cdot \mathrm{dm}^{-3} \mathrm{LiTFSI} ; \boldsymbol{\square}, \mathrm{DMC}+1 \mathrm{~mol} \cdot \mathrm{dm}^{-3} \mathrm{LiPF}_{6} ; \square, \mathrm{DMC}+1 \mathrm{~mol} \cdot \mathrm{dm}^{-3}$ LiTFSI; $\diamond$ EMC + $1 \mathrm{~mol} \cdot \mathrm{dm}^{-3} \mathrm{LiPF}_{6} ; \diamond, \mathrm{EMC}+1 \mathrm{~mol} \cdot \mathrm{dm}^{-3} \mathrm{LiTFSI} ; \boldsymbol{\Delta}, \mathrm{DEC}+1$ $\mathrm{mol} \cdot \mathrm{dm}^{-3} \mathrm{LiPF}_{6} ; \triangle, \mathrm{DEC}+1 \mathrm{~mol} \cdot \mathrm{dm}^{-3}$ iTFSI; expressed: a) as $\mathrm{CO}_{2}$ mole fraction, b) as $\ln \left(K_{\mathrm{H}} / \mathrm{p}^{0}\right)$ and 0.1 MPa. Lines represent the smoothed data using the parameters in table 4.

a)
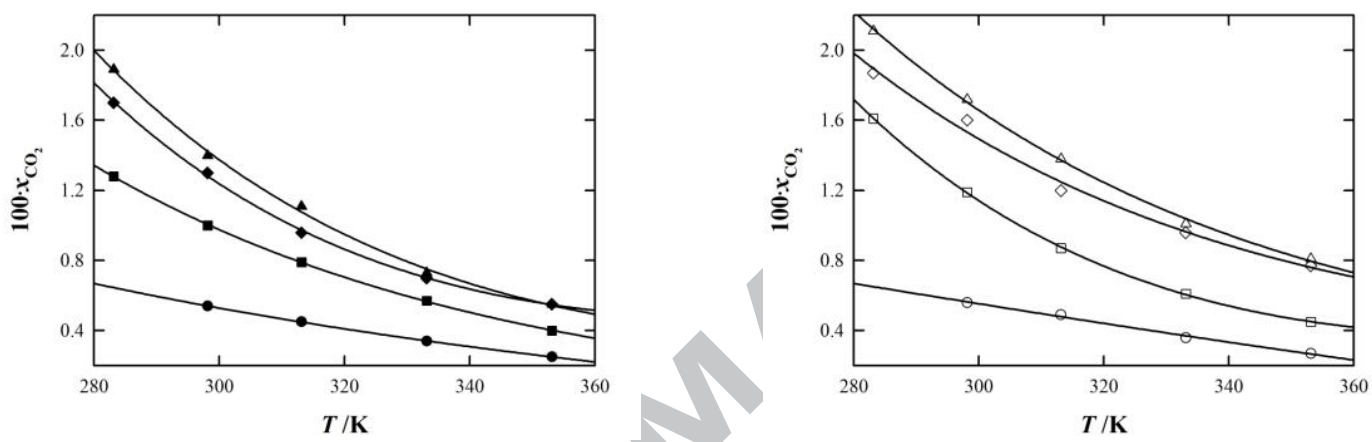

b)
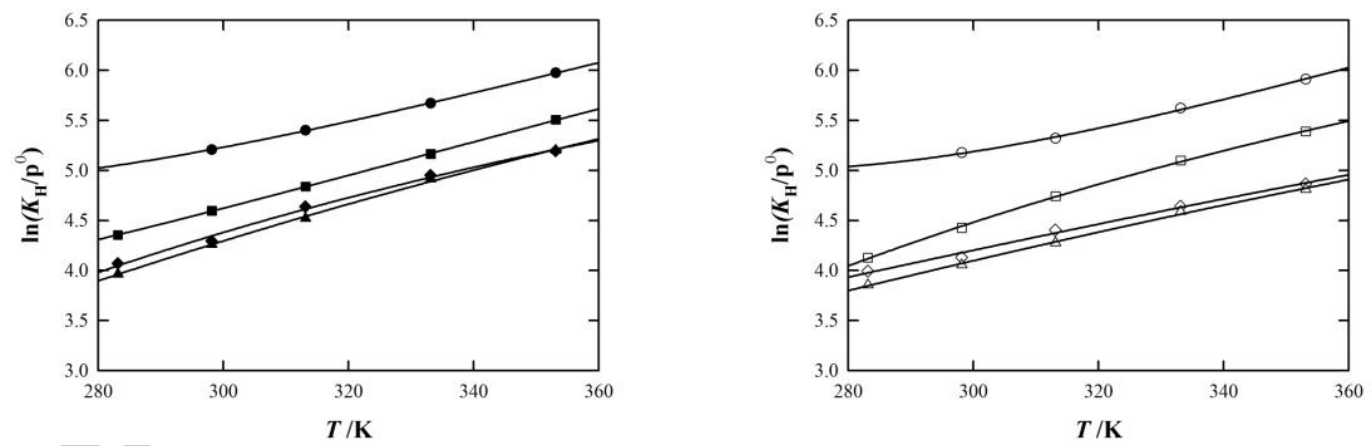
Figure 3. $\mathrm{CO}_{2}$ solubility in: black bars, pure solvents; red bars, electrolytes containing $1 \mathrm{~mol} \cdot \mathrm{dm}^{-3} \mathrm{LiPF}_{6}$; green bars, electrolytes containing $1 \mathrm{~mol} \cdot \mathrm{L}^{-1}$ of LiTFSI at: a) $T=298$ $\mathrm{K}$; b) $353 \mathrm{~K}$ and $0.1 \mathrm{MPa}$.

a)

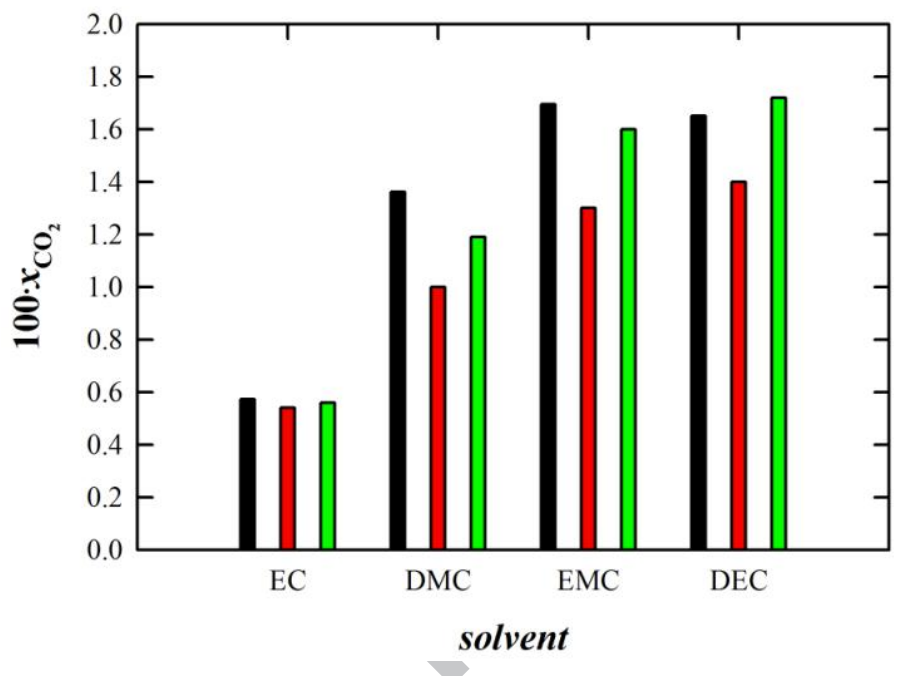

b)

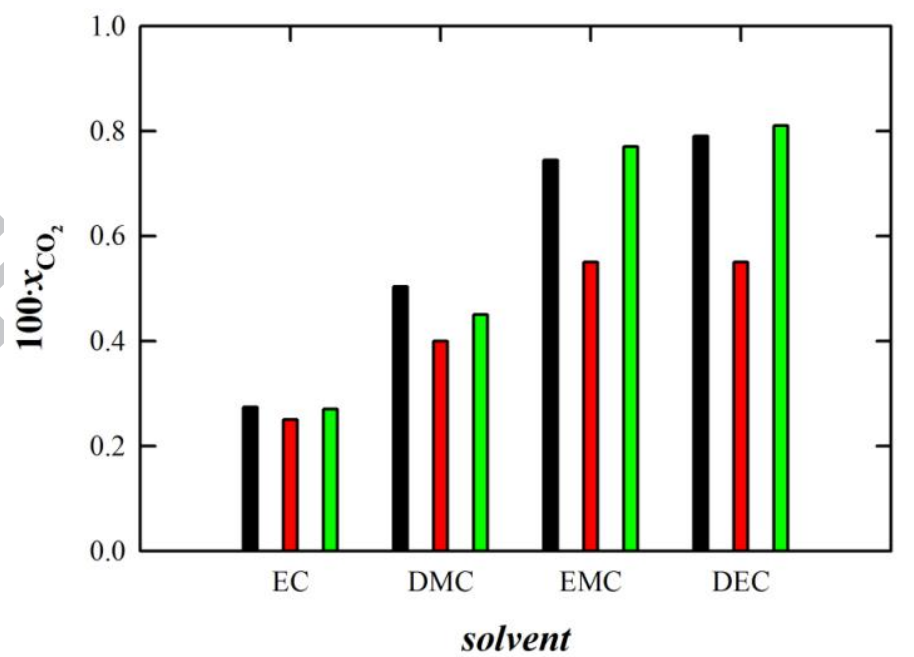


Figure 4. $\mathrm{CO}_{2}$ solubility in: black bars, carbonate mixtures (50:50) wt \%; red bars, electrolytes containing $1 \mathrm{~mol} \cdot \mathrm{dm}^{-3} \mathrm{LiPF}_{6}$; green bars, electrolytes containing $1 \mathrm{~mol} \cdot \mathrm{dm}^{-3}$ LiTFSI ; yellow bars, electrolytes containing $1 \mathrm{~mol} \cdot \mathrm{dm}^{-3} \mathrm{LiFAP}$ at: a) $T=298 \mathrm{~K}$; b) 353 $\mathrm{K}$ and $0.1 \mathrm{MPa}$.

a)

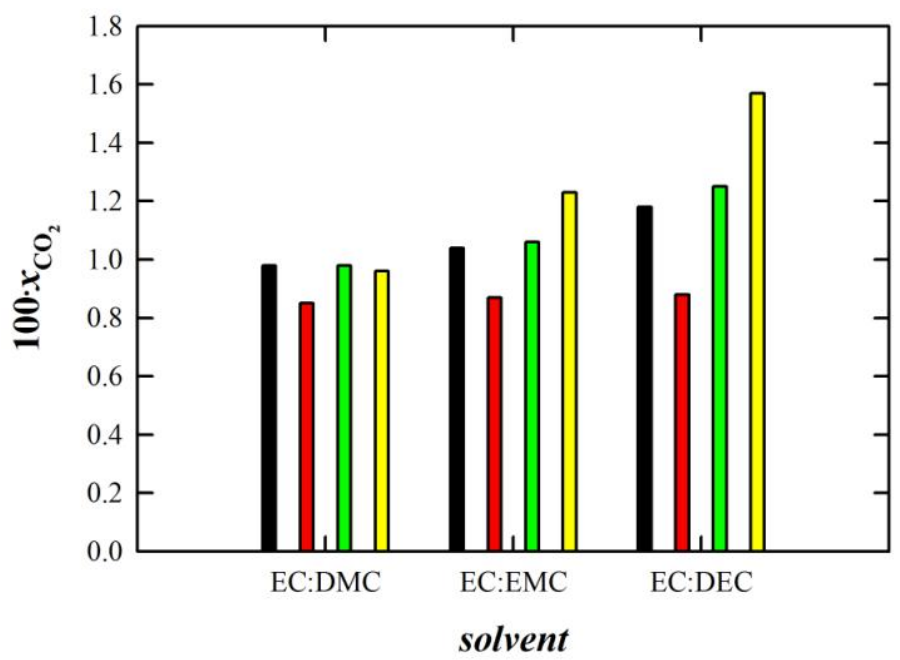

b)

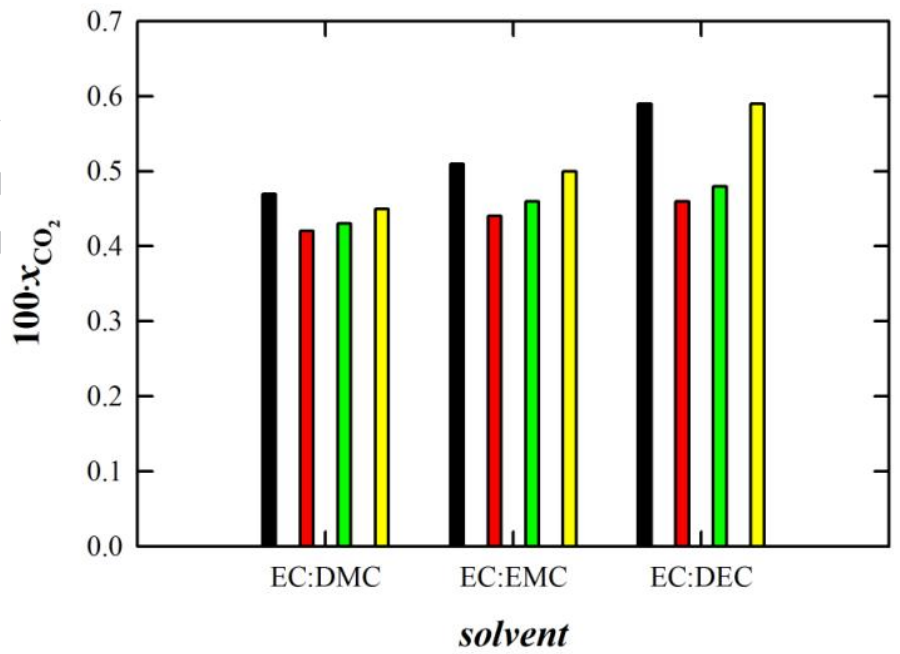


Figure 5. $\mathrm{CO}_{2}$ solubility in (50:50) wt \% EC:DMC-based electrolytes containing; and dotted line: $\mathrm{LiPF}_{6} ; \square$, and dashed line: LiTFSI salt as a function of the lithium salt (LiX) concentration in solution expressed in mol $\cdot \mathrm{dm}^{-3}$ at $T=298.15 \mathrm{~K}$ and $0.1 \mathrm{MPa}$. The solid line represents the $\mathrm{CO}_{2}$ solubility in (50:50) wt \% EC:DMC mixture without salt at $T=298.15 \mathrm{~K}$ and $0.1 \mathrm{MPa}$.

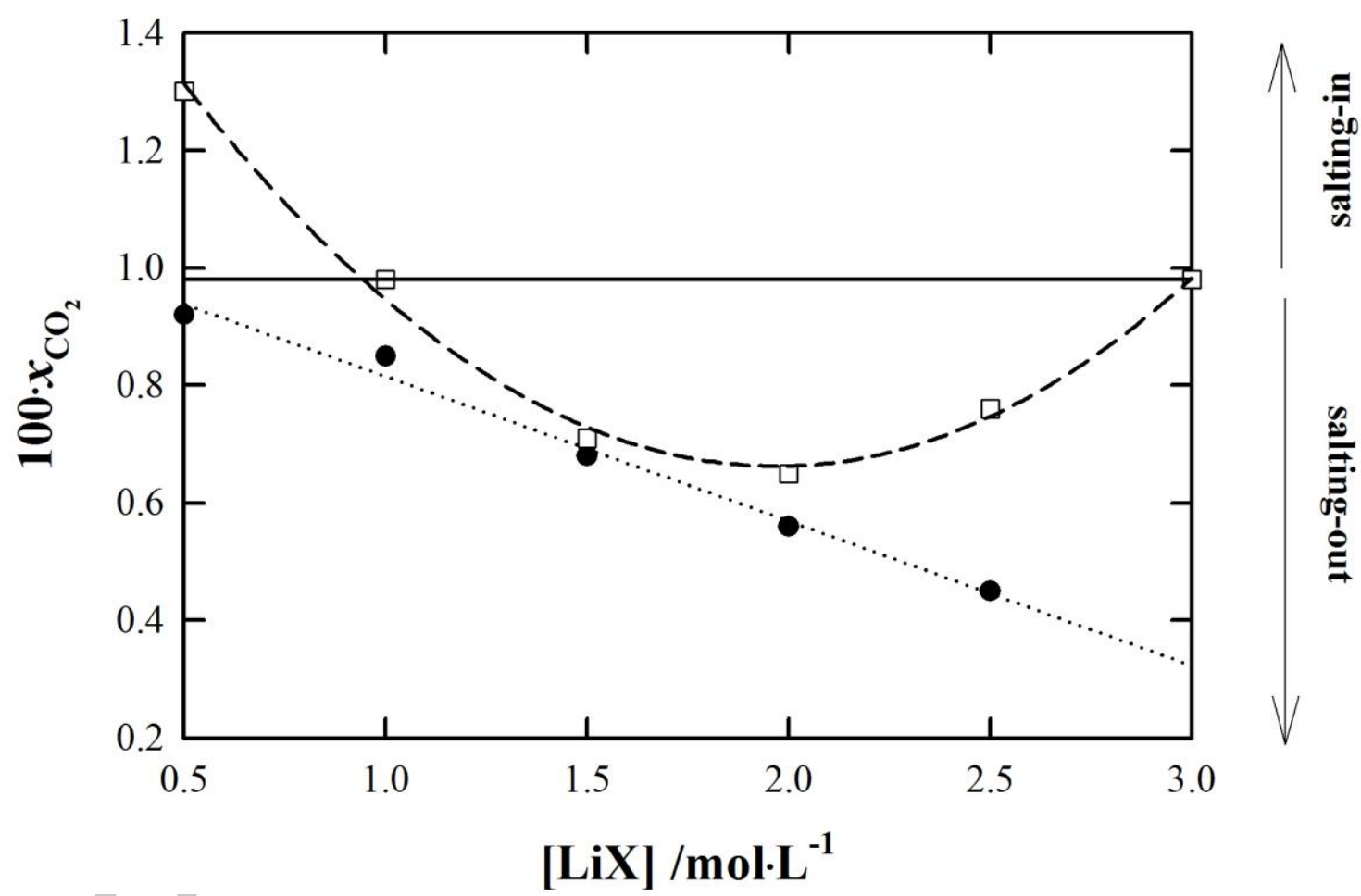


Figure 6. Comparison between experimental data (bars) of the $\mathrm{CO}_{2}$ solubility, expressed in Henry's law constant, in a) $\mathrm{EC}+1 \mathrm{~mol} \cdot \mathrm{dm}^{-3} \mathrm{LiPF}_{6}$; b) $\mathrm{EC}+1 \mathrm{~mol} \cdot \mathrm{dm}^{-3}$ LiTFSI from table 3 with those calculated by COSMOThermX (dashed lines) as a function of temperature and atmospheric pressure.

a)

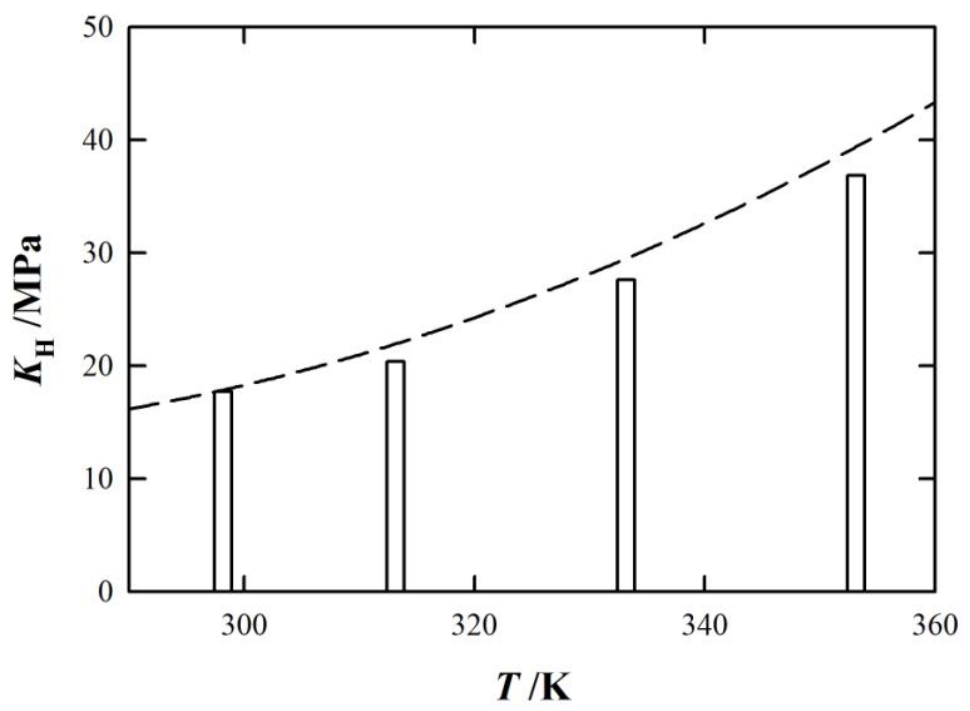

b)

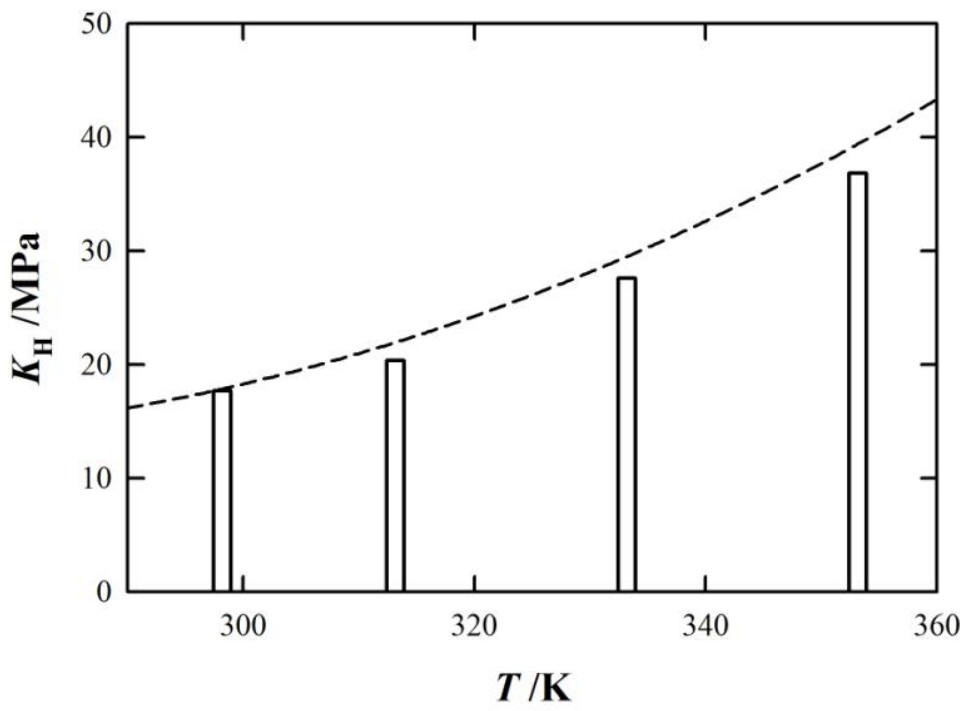


Figure 7. Comparison between experimental data of $\mathrm{CO}_{2}$ solubility, expressed in Henry's law constant, in electrolytes containing $1 \mathrm{~mol} \cdot \mathrm{dm}^{-3}$ LiTFSI dissolved in: $\bullet$, EC; $\square$, DMC; $\mathbf{\Lambda}$, DEC with those calculated by COSMOThermX: solid, dashed and dotted lines as a function of temperature and atmospheric pressure, respectively.

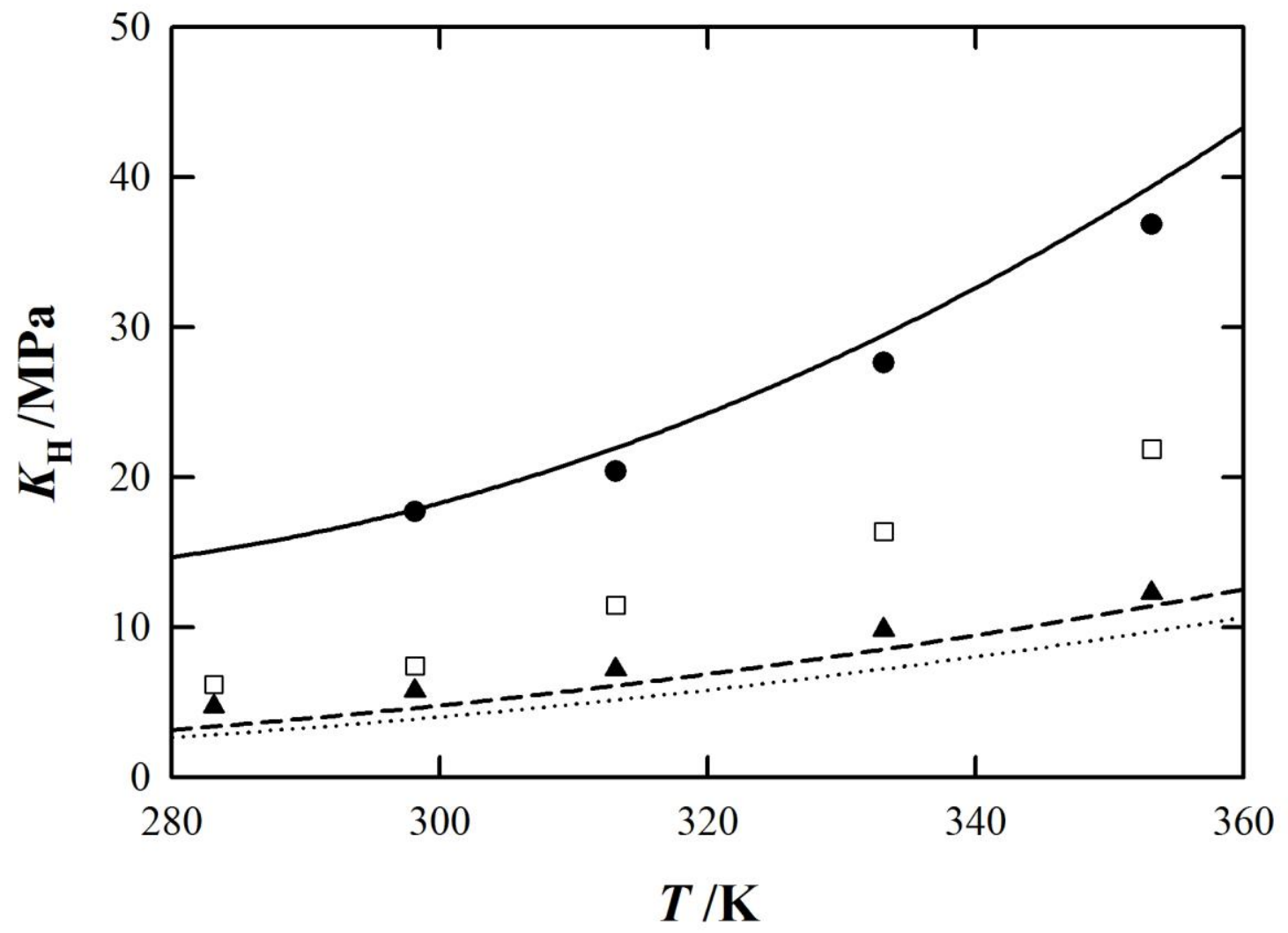


Figure 8. COSMOThermX calculations of the $\mathrm{CO}_{2}$ solubility in: black bars, pure carbonate or (50:50) wt \% carbonate mixtures; red bars, electrolytes containing 1 $\mathrm{mol} \cdot \mathrm{dm}^{-3}$ of $\mathrm{LiPF}_{6}$; green bars, electrolytes containing $1 \mathrm{~mol} \cdot \mathrm{dm}^{-3}$ LiTFSI ; yellow bars, electrolytes containing $1 \mathrm{~mol} \cdot \mathrm{dm}^{-3} \mathrm{LiFAP}$ at: a) $T=298 \mathrm{~K}$; b) $353 \mathrm{~K}$ and $0.1 \mathrm{MPa}$.

a)

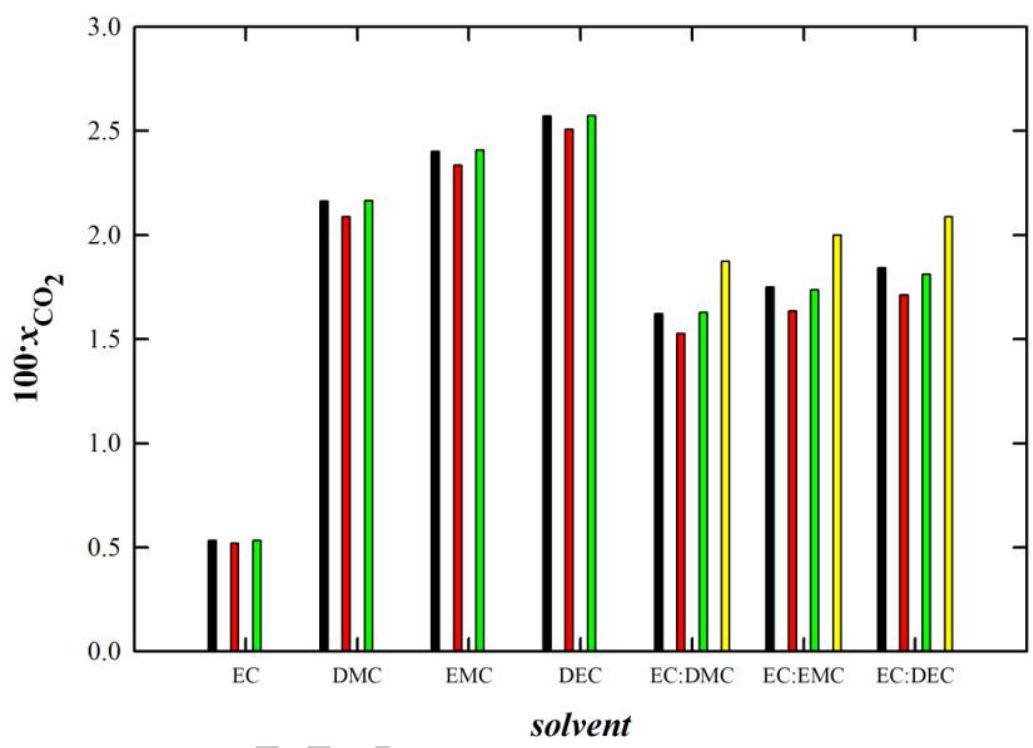

b)

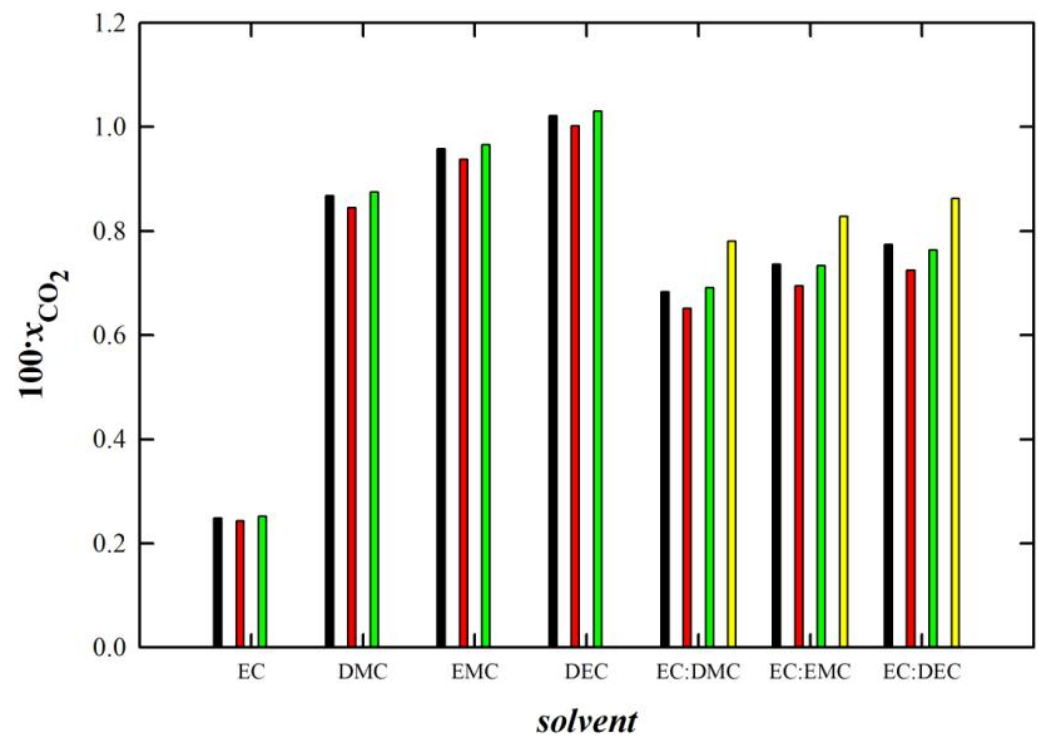


Figure 9. COSMOTherm X calculations of the $\mathrm{CO}_{2}$ solubility in (50:50) wt \% EC:DMC-based electrolytes containing; $\bullet$, and dotted line: $\mathrm{LiPF}_{6}$; $\square$, and dashed line: LiTFSI salt defined as an ion-pair; $\mathbf{\square}$, and dashed-dotted line: LiTFSI salt defined as two individual ions; $\bullet$, and dashed-dotted-dotted line: LiTFSI salt defined using a metafile as a function of the lithium salt (LiX) concentration in solution expressed in $\mathrm{mol} \cdot \mathrm{dm}^{-3}$ at $T=298.15 \mathrm{~K}$ and $0.1 \mathrm{MPa}$. The solid line represents the $\mathrm{CO}_{2}$ solubility in (50:50) wt \% EC:DMC mixture without salt at $T=298.15 \mathrm{~K}$ and $0.1 \mathrm{MPa}$.

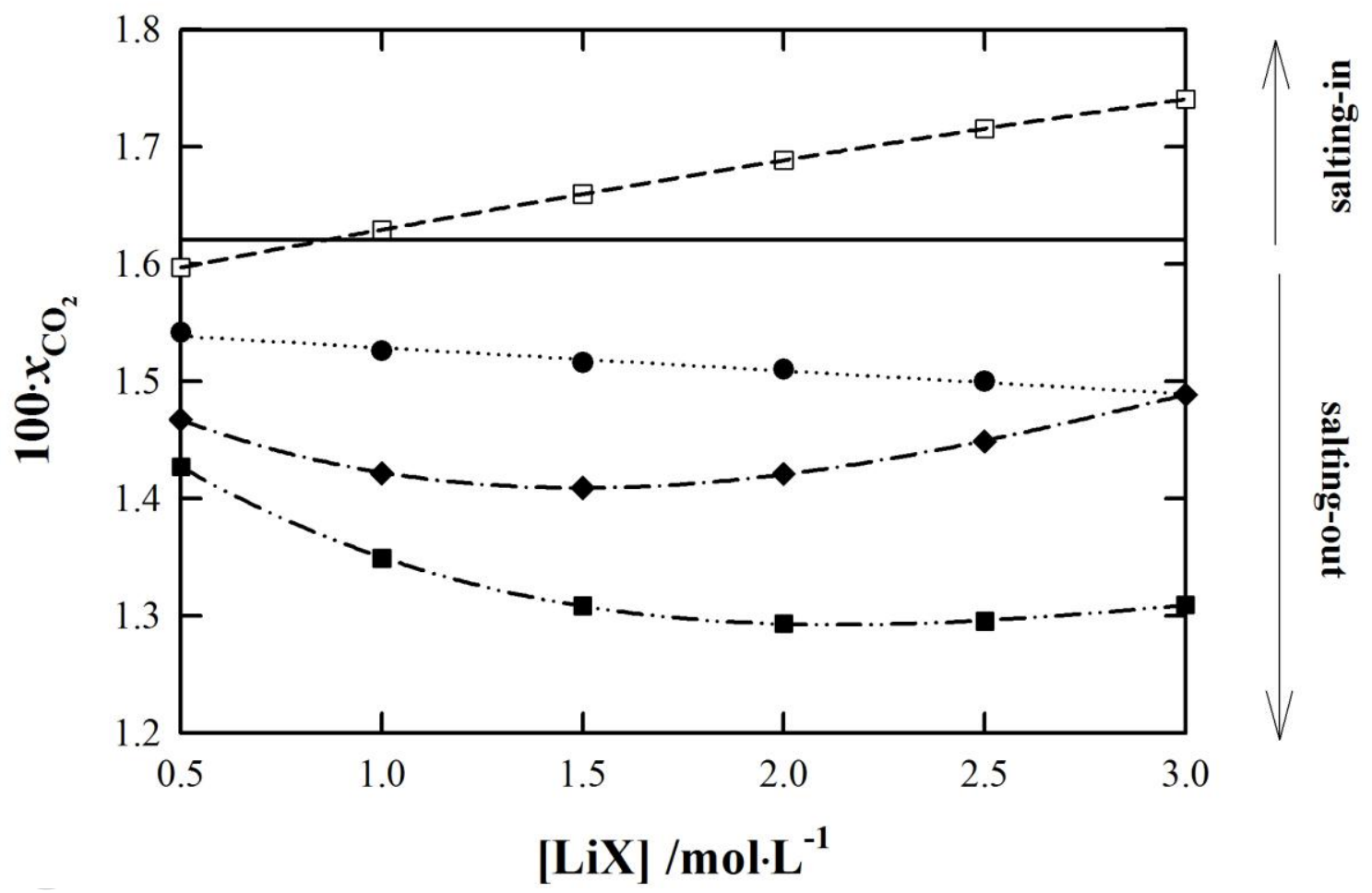


Table 1. Source, abbreviation, purity, and water content for each chemical sample reported during this work.

\begin{tabular}{|c|c|c|c|c|}
\hline Chemical name & Source & Abbreviation & $\begin{array}{c}\text { Mole fraction } \\
\text { Purity }\end{array}$ & $\frac{\text { er content }}{1 \times 10^{-6}}$ \\
\hline ethylene carbonate & Aldrich & $\mathrm{EC}$ & 0.9999 & $<10$ \\
\hline dimethyl carbonate & Aldrich & DMC & 0.9999 & $<10$ \\
\hline ethyl methyl carbonate & Aldrich & EMC & 0.9999 & $<10$ \\
\hline diethyl carbonate & Aldrich & DEC & 0.9999 & $<10$ \\
\hline lithium hexafluorophosphate & Aldrich & $\mathrm{LiPF}_{6}$ & 0.9999 & $<5$ \\
\hline lithium bis(trifluoromethylsulfonyl)imide & Solvionic & iTFSI & 0.9999 & $<5$ \\
\hline $\begin{array}{l}\text { lithium } \\
\text { tris(pentafluoroethane)trifluorurophosphate }\end{array}$ & Merck & LiFAP & 0.9999 & $<10$ \\
\hline $\begin{array}{l}\text { sodium hydroxide standard solution, } \\
\qquad 0.5 \mathrm{~mol} \cdot \mathrm{dm}^{-3}\end{array}$ & Riedel-de Haen & $\mathrm{NaOH}$ & - & - \\
\hline $\begin{array}{l}\text { hydrochloric acid standard solution, } \\
\qquad 1 \mathrm{~mol} \cdot \mathrm{dm}^{-3}\end{array}$ & Riedel-de Haen & $\mathrm{HCl}$ & - & - \\
\hline carbon dioxide & AGA/Linde Gaz & $\mathrm{CO}_{2}$ & 0.99995 & - \\
\hline argon & AGA/Linde Gaz & $\mathrm{Ar}$ & 0.999997 & - \\
\hline
\end{tabular}

a, all LiFAP electrolytes were purchased from Merck in solution containing already $1 \mathrm{~mol} \cdot \mathrm{dm}^{-3}$ of LiFAP salt dissolved in each inyestigated binary solvent mixture. 
Table 2. Experimental density values of pure solvents as well as of electrolytes containing $1 \mathrm{~mol} \cdot \mathrm{L}^{-1}$ of lithium salt $\left(\mathrm{LiPF}_{6}\right.$ or LiTFSI) at $T=298.15 \mathrm{~K}$ and atmospheric pressure.

\begin{tabular}{cccccc}
\hline \multicolumn{5}{c}{$\rho / \mathrm{g} \cdot \mathrm{cm}^{-3}$ at $T=298.15 \mathrm{~K}^{\mathrm{a}}$} \\
\hline Solvent & pure solvent & $\mathrm{LiPF}_{6}$ & $100 \cdot \delta^{\mathrm{b}}$ & LiTFSI & $100 \cdot \delta^{\mathrm{b}}$ \\
\hline EC & $1.35^{\mathrm{c}}$ & 1.40 & -3.6 & 1.42 & -5.1 \\
DMC & 1.07 & 1.14 & -6.6 & 1.16 & -8.5 \\
EMC & 1.01 & 1.09 & -8.2 & 1.13 & -12.2 \\
DEC & 0.97 & 1.05 & -8.4 & 1.10 & -13.5 \\
\hline
\end{tabular}

a, precision and accuracy of the reported experimental data are close to $\left(1 \times 10^{-2}\right.$ and $\left.5 \times 10^{-2}\right) \mathrm{g} \cdot \mathrm{cm}^{-3}$, respectively.

b, $100 \cdot \delta=\frac{\rho_{\text {puresolvent }}-\rho_{\text {electolyte }}}{\rho_{\text {puresolvent }}}$

c, measured in its sub-cooled liquid state after heating at $T=353 \mathrm{~K}$. 
Table 3. Experimental values of $\mathrm{CO}_{2}$ solubility in selected electrolytes containing 1 $\mathrm{mol} \cdot \mathrm{dm}^{-3}$ of lithium salt $\left(\mathrm{LiPF}_{6}\right.$ or LiTFSI) expressed both as Henry's law constants, $K_{\mathrm{H}}$ and as $\mathrm{CO}_{2}$ mole fraction, $x_{2}$, at atmospheric pressure. $\delta$ are relative deviations calculated from each correlation reported in table 4.

\begin{tabular}{|c|c|c|c|c|}
\hline Electrolyte & $T / \mathrm{K}$ & $10^{2} \cdot x_{\mathrm{CO} 2}{ }^{\mathrm{a}}$ & $K_{\mathrm{H}} / \mathrm{MPa}^{\mathrm{a}}$ & $100 \cdot \delta$ \\
\hline \multirow{4}{*}{$\mathrm{EC}+1 \mathrm{~mol} \cdot \mathrm{dm}^{-3} \mathrm{LiPF}_{6}$} & 298.15 & 0.54 & 18.27 & -0.15 \\
\hline & 313.15 & 0.45 & 22.15 & +0.40 \\
\hline & 333.15 & 0.34 & 29.03 & -0.38 \\
\hline & 353.15 & 0.25 & 39.27 & +0.14 \\
\hline \multirow{4}{*}{$\mathrm{EC}+1 \mathrm{~mol} \cdot \mathrm{dm}^{-3}$ LiTFSI } & 298.15 & 0.56 & 17.69 & +0.60 \\
\hline & 313.15 & 0.49 & 20.40 & -1.63 \\
\hline & 333.15 & 0.36 & 27.63 & +1.55 \\
\hline & 353.15 & 0.27 & 36.85 & -0.56 \\
\hline \multirow{5}{*}{$\mathrm{DMC}+1 \mathrm{~mol} \cdot \mathrm{dm}^{-3} \mathrm{LiPF}_{6}$} & 283.15 & 1.28 & 7.79 & -0.22 \\
\hline & 298.15 & 1.00 & 9.91 & +0.38 \\
\hline & 313.15 & 0.79 & 12.63 & +0.16 \\
\hline & 333.15 & 0.57 & 17.48 & -0.61 \\
\hline & 353.15 & 0.40 & 24.58 & +0.29 \\
\hline \multirow{5}{*}{$\mathrm{DMC}+1 \mathrm{~mol} \cdot \mathrm{dm}^{-3}$ LiTFSI } & 283.15 & 1.61 & 6.20 & +0.80 \\
\hline & 298.15 & 1.19 & 8.36 & -1.80 \\
\hline & 313.15 & 0.87 & 11.46 & +0.44 \\
\hline & 333.15 & 0.61 & 16.38 & +1.24 \\
\hline & 353.15 & 0.45 & 21.88 & -0.71 \\
\hline \multirow{5}{*}{$\mathrm{EMC}+1 \mathrm{~mol} \cdot \mathrm{dm}^{-3} \mathrm{LiPF}_{6}$} & 283.15 & 1.70 & 5.85 & +2.11 \\
\hline & 298.15 & 1.30 & 7.32 & -5.42 \\
\hline & 313.15 & 0.96 & 10.35 & +2.55 \\
\hline & 333.15 & 0.70 & 14.12 & +1.91 \\
\hline & 353.15 & 0.55 & 18.06 & -1.38 \\
\hline \multirow{5}{*}{ EMC $+1 \mathrm{~mol} \mathrm{dm}^{-3} \cdot$ LiTFSI } & 283.15 & 1.87 & 5.43 & +1.74 \\
\hline & 298.15 & 1.60 & 6.23 & -4.70 \\
\hline & 313.15 & 1.20 & 8.17 & +2.72 \\
\hline & 333.15 & 0.96 & 10.36 & +0.97 \\
\hline & 353.15 & 0.77 & 12.98 & -0.92 \\
\hline \multirow{5}{*}{$\mathrm{DEC}+1 \mathrm{~mol} \cdot \mathrm{dm}^{-3} \mathrm{LiPF} 6$} & 283.15 & 1.89 & 5.27 & +0.26 \\
\hline & 298.15 & 1.40 & 7.10 & +0.24 \\
\hline & 313.15 & 1.11 & 9.19 & -2.03 \\
\hline & 333.15 & 0.73 & 13.62 & +2.46 \\
\hline & 353.15 & 0.55 & 18.14 & -0.98 \\
\hline \multirow{5}{*}{$\mathrm{DEC}+1 \mathrm{~mol} \cdot \mathrm{dm}^{-3}$ LiTFSI } & 283.15 & 2.11 & 4.73 & +0.87 \\
\hline & 298.15 & 1.72 & 5.78 & -1.43 \\
\hline & 313.15 & 1.38 & 7.21 & -0.93 \\
\hline & 333.15 & 1.01 & 9.85 & +2.68 \\
\hline & 353.15 & 0.81 & 12.28 & -1.26 \\
\hline
\end{tabular}

a, precision and accuracy of the reported experimental data are close to (1 and 15) \%, respectively.[22] 
Table 4. Parameters of equation (4) used to smooth the experimental $\mathrm{CO}_{2}$ solubility results from table 3 along with the relative average absolute deviation of the fit $(R A A D)$.

\begin{tabular}{lcccc}
\hline Electrolyte & $A_{0}$ & $A_{1}$ & $A_{2}$ & 100.RAAD \\
\hline $\mathrm{EC}+1 \mathrm{~mol} \cdot \mathrm{dm}^{-3} \mathrm{LiPF}_{6}$ & +17.844 & $-6.5002 \times 10^{3}$ & $+8.1492 \times 10^{5}$ & 0.3 \\
$\mathrm{DMC}+1 \mathrm{~mol} \cdot \mathrm{dm}^{-3} \mathrm{LiPF}_{6}$ & +16.132 & $-5.4539 \times 10^{3}$ & $+6.0027 \times 10^{5}$ & 0.3 \\
$\mathrm{EMC}+1 \mathrm{~mol} \cdot \mathrm{dm}^{-3} \mathrm{LiPF}_{6}$ & +9.5592 & $-1.4359 \times 10^{3}$ & $-3.5264 \times 10^{4}$ & 2.7 \\
$\mathrm{DEC}+1 \mathrm{~mol} \cdot \mathrm{dm}^{-3} \mathrm{LiPF}_{6}$ & +12.266 & $-3.0595 \times 10^{3}$ & $+2.0055 \times 10^{5}$ & 1.2 \\
\hline $\mathrm{EC}+1 \mathrm{~mol} \cdot \mathrm{dm}^{-3} \mathrm{LiTFSI}$ & +20.510 & $-8.3008 \times 10^{3}$ & $+1.1112 \times 10^{6}$ & 1.1 \\
$\mathrm{DMC}+1 \mathrm{~mol} \cdot \mathrm{dm}^{-3} \mathrm{LiTFSI}$ & +10.457 & $-1.7591 \times 10^{3}$ & $-1.0021 \times 10^{4}$ & 1.0 \\
$\mathrm{EMC}+1 \mathrm{~mol} \cdot \mathrm{dm}^{-3} \mathrm{LiTFSI}$ & +11.417 & $-3.1341 \times 10^{3}$ & $+2.9089 \times 10^{5}$ & 2.2 \\
$\mathrm{DEC}+1 \mathrm{~mol} \cdot \mathrm{dm}^{-3} \mathrm{LiTFSI}$ & +11.367 & $-3.0466 \times 10^{3}$ & $+2.5982 \times 10^{5}$ & 1.4 \\
\hline
\end{tabular}


Table 5. Thermodynamic parameters of $\mathrm{CO}_{2}$ with selected electrolytes based on a pure carbonate solvent and $\mathrm{CO}_{2}$ solubility expressed in Henry's Law constant for electrolytes studied at $T=298.15 \mathrm{~K}$ and $0.1 \mathrm{MPa}$.

\begin{tabular}{|c|c|c|c|c|c|}
\hline \multirow{2}{*}{ Electrolyte } & $K_{\mathrm{H}}{ }^{\mathrm{a}}$ & $\Delta_{\mathrm{dis}} G^{0 \mathrm{a}}$ & $\Delta_{\mathrm{dis}} H^{0 \mathrm{a}}$ & $\Delta_{\text {mix }} H^{0 \text { a }}$ & $\Delta_{\mathrm{dis}} S^{0 \mathrm{a}}$ \\
\hline & $\mathrm{MPa}$ & $\mathrm{kJ} \cdot \mathrm{mol}^{-1}$ & $\mathrm{~kJ} \cdot \mathrm{mol}^{-1}$ & $\mathrm{~kJ} \cdot \mathrm{mol}^{-1}$ & $\mathrm{~J} \cdot \mathrm{K}^{-1} \cdot \mathrm{mol}^{-1}$ \\
\hline $\mathrm{EC}+1 \mathrm{~mol} \cdot \mathrm{dm}^{-3} \mathrm{LiPF}_{6}$ & 18.27 & 12.94 & -12.26 & 4.64 & -84.53 \\
\hline $\mathrm{DMC}+1 \mathrm{~mol} \cdot \mathrm{dm}^{-3} \mathrm{LiPF}_{6}$ & 9.91 & 11.42 & -14.55 & 2.35 & -87.08 \\
\hline $\mathrm{EMC}+1 \mathrm{~mol} \cdot \mathrm{dm}^{-3} \mathrm{LiPF}_{6}$ & 7.32 & 10.77 & -13.64 & 3.26 & -81.86 \\
\hline $\mathrm{DEC}+1 \mathrm{~mol} \cdot \mathrm{dm}^{-3} \mathrm{LiPF}_{6}$ & 7.10 & 10.58 & -11.51 & 5.39 & -74.09 \\
\hline $\mathrm{EC}+1 \mathrm{~mol} \cdot \mathrm{dm}^{-3} \mathrm{LiTFSI}$ & 17.69 & 12.85 & -11.84 & .06 & -82.81 \\
\hline $\mathrm{DMC}+1 \mathrm{~mol} \cdot \mathrm{dm}^{-3}$ LiTFSI & 8.36 & 10.98 & & 1.64 & -88.04 \\
\hline $\mathrm{EMC}+1 \mathrm{~mol} \cdot \mathrm{dm}^{-3}$ LiTFSI & 6.23 & 10.25 & & 6.06 & -70.71 \\
\hline $\mathrm{DEC}+1 \mathrm{~mol} \cdot \mathrm{dm}^{-3}$ LiTFSI & 5.78 & 10.07 & -11.62 & 5.28 & -72.75 \\
\hline
\end{tabular}

a, accuracy of the reported data are close to $15 \%$. 
Table 6. Experimental density values of (50:50) wt \% of carbonate binary mixtures, as well as of their solutions containing $1 \mathrm{~mol} \cdot \mathrm{dm}^{-3}$ lithium salt (LiFAP, $\mathrm{LiPF}_{6}$ or LiTFSI) at $T=298.15 \mathrm{~K}$ and atmospheric pressure.

\begin{tabular}{lccccccc}
\hline & \multicolumn{7}{c}{$\rho / \mathrm{g} \cdot \mathrm{cm}^{-3}$ at $T=298.15 \mathrm{~K}^{\mathrm{a}}$} \\
\hline Solvent & No salt & LiFAP & $100 \cdot \delta^{\mathrm{b}}$ & $\mathrm{LiPF}_{6}$ & $100 \cdot \delta^{\mathrm{b}}$ & LiTFSI & $100 \cdot \delta^{\mathrm{b}}$ \\
\hline EC:DMC & 1.23 & 1.34 & -8.9 & 1.29 & -4.9 & 1.31 & -6.5 \\
EC:EMC & 1.19 & 1.32 & -10.9 & 1.27 & -6.7 & 1.29 & -8.4 \\
EC:DEC & 1.09 & 1.30 & -19.3 & 1.25 & -14.7 & 1.28 & -17.4 \\
\hline
\end{tabular}

a, precision and accuracy of the reported experimental data are close to $\left(1 \times 10^{-2}\right.$ and $\left.5 \times 10^{-2}\right) \mathrm{g} \cdot \mathrm{cm}^{-3}$, respectively.

b, $100 \cdot \delta=\frac{\rho_{\text {puresolvent }}-\rho_{\text {electolyte }}}{\rho_{\text {puresolvent }}}$ 


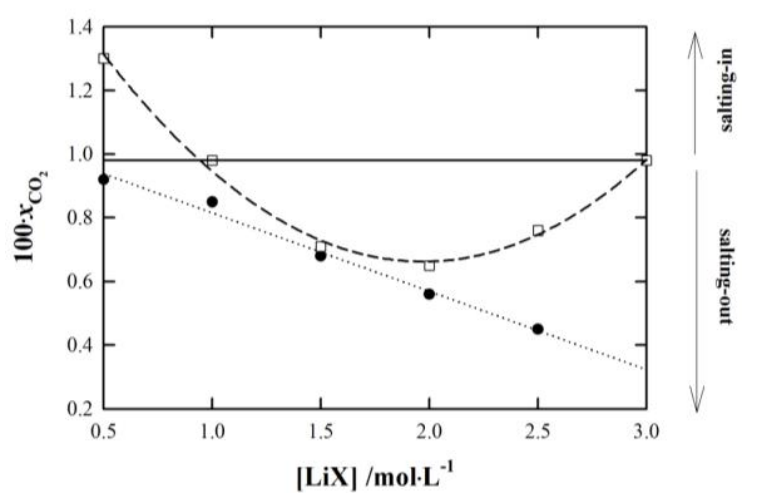




\section{Highlights}

- $\mathrm{CO}_{2}$ solubility is measured in pure alkylcarbontes and thier binary mixtures.

- The $\mathrm{CO}_{2}$ solubility varies significantly for concentration $\mathrm{LiPF}_{6}$, LiTFSI and LiFAP salt.

- The dissolution of the $\mathrm{CO}_{2}$ in all solvents is entropy-driven and exothermic.

- $\mathrm{CO}_{2}$ solubilities were predicted using COSMOthermX and compared to measurements . 